\title{
FLOWTRAN-TF CODE BENCHMARKING (U)
} by

Westinghouse Savannah River Company Savannah River Site Aiken, South Carolina 29808

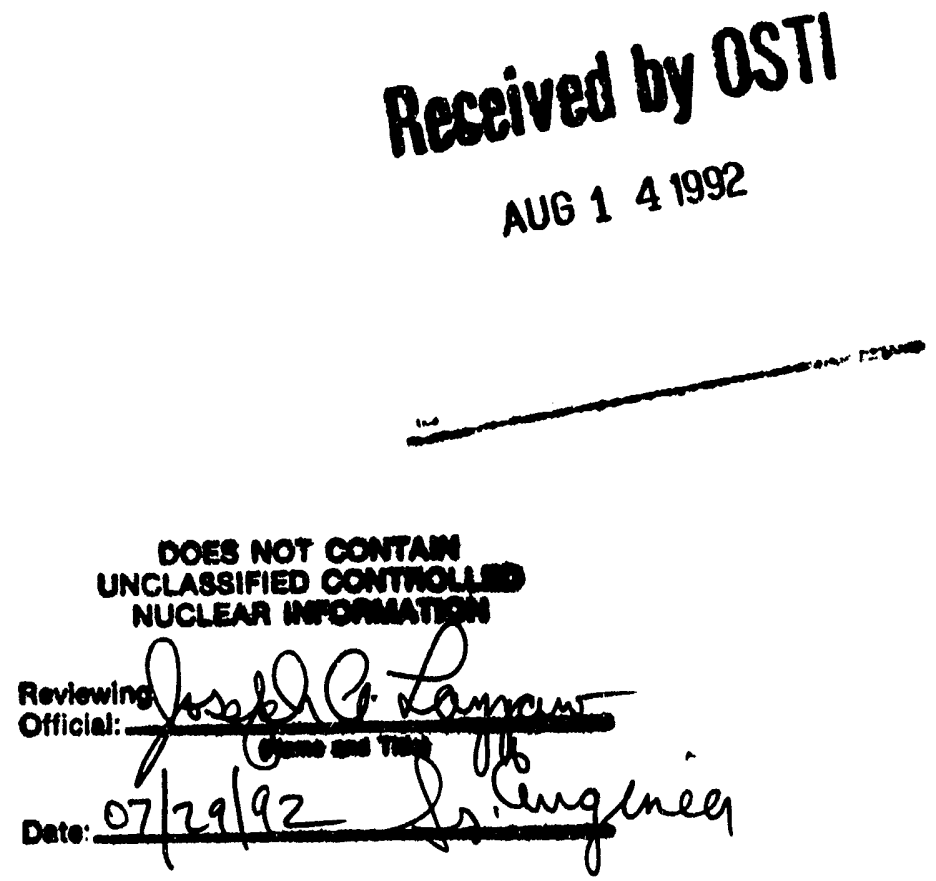

This report was prepared in connection with work done under Contract No. DE-AC09-89SR18035 with the U.S. Department of Energy. By acceptance of this report, the publisher and/or recipient acknowledges the U.S. Government's right to retain a nonexclusive, royalty-free license in and to any copyright covering this report, along with the right to reproduce and to authorize others to reproduce all or part of the copyrighted report. 


\section{DISCLAIMER}

This report was prepared as an account of work sponsored by an agency of the United States Government. Neither the United States Government nor any agency thereof, nor any of their employees, makes any warranty, express or implied, or assumes any legal liability or responsibility for the accuracy, completeness, or usefulness of any information, apparatus, product, or process disclosed, or represents that its use would not infringe privately owned rights. Reference herein to any specific commercial product, process, or service by trade name, trademark, manufacturer, or otherwise does not necessarily constitute or imply its endorsement, recommendation, or favoring by the United States Government or any agency thereof. The views and opinions of authors expressed herein do not necessarily state or reflect those of the United States Government or any agency thereof.

This report has been reproduced directly from the best available copy.

Available to DOE and DOE contractors from the Office of Scientific and Technical Information, P.O. Box 62, Oak Ridge, TN 37831; prices available from (615) 576-8401, FTS 626-8401.

Available to the public from the National Technical Information Service, U.S. Department of Commerce, 5285 Port Royal Rd., Springfield, VA 22161. 
NRTSC

WSRC-TR-90-414 NUCLEAR REACTOR TECHNOLOGY AND SCIENTIFIC COMPUTATIONS

KEYWORDS: LOCA

ECS (EMERGENCY

COOLING SYSTEM)

ASSEMBLY LIMITS

RETENTION: PERMANENT

FLOWTRAN-TF Code Benchmarking (U) edited by

G. P. Flach

with contributions by

S. E. Aleman

G. P. Flach

S. Y. Lee

F. G. Smith, III

ISSUED: December, 1990

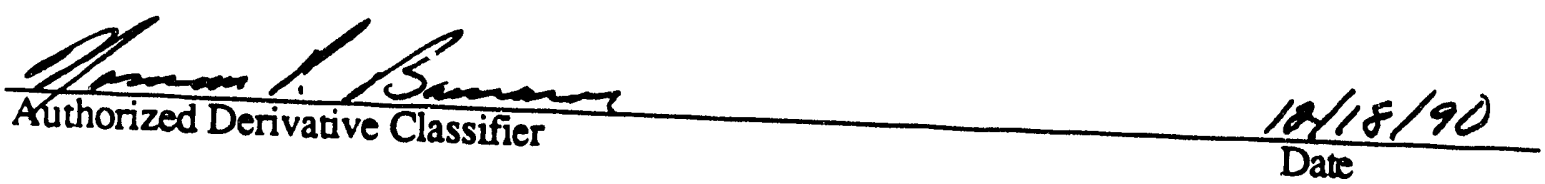

Westinghouse Savannah River Company

Savannah River Laboratory

Aiken, SC 29802 
PROJECT: 89-021-1

DOCUMENT: WSRC-TR-90-414

TITLE: FLOWTRAN-TF Code Benchmarking (U)

REVISION NUMBER: 0

$\frac{A}{A . \text { L. KIELPINSKI, TECHNICAL REVIEWER }}$

\begin{tabular}{ll} 
Ganse. $\mathcal{E}$ Lamine & $12 \cdot 17 \cdot 4,0$ \\
\hline B. LAURINAT, TECHNICAL REVIEWER & DATE
\end{tabular}
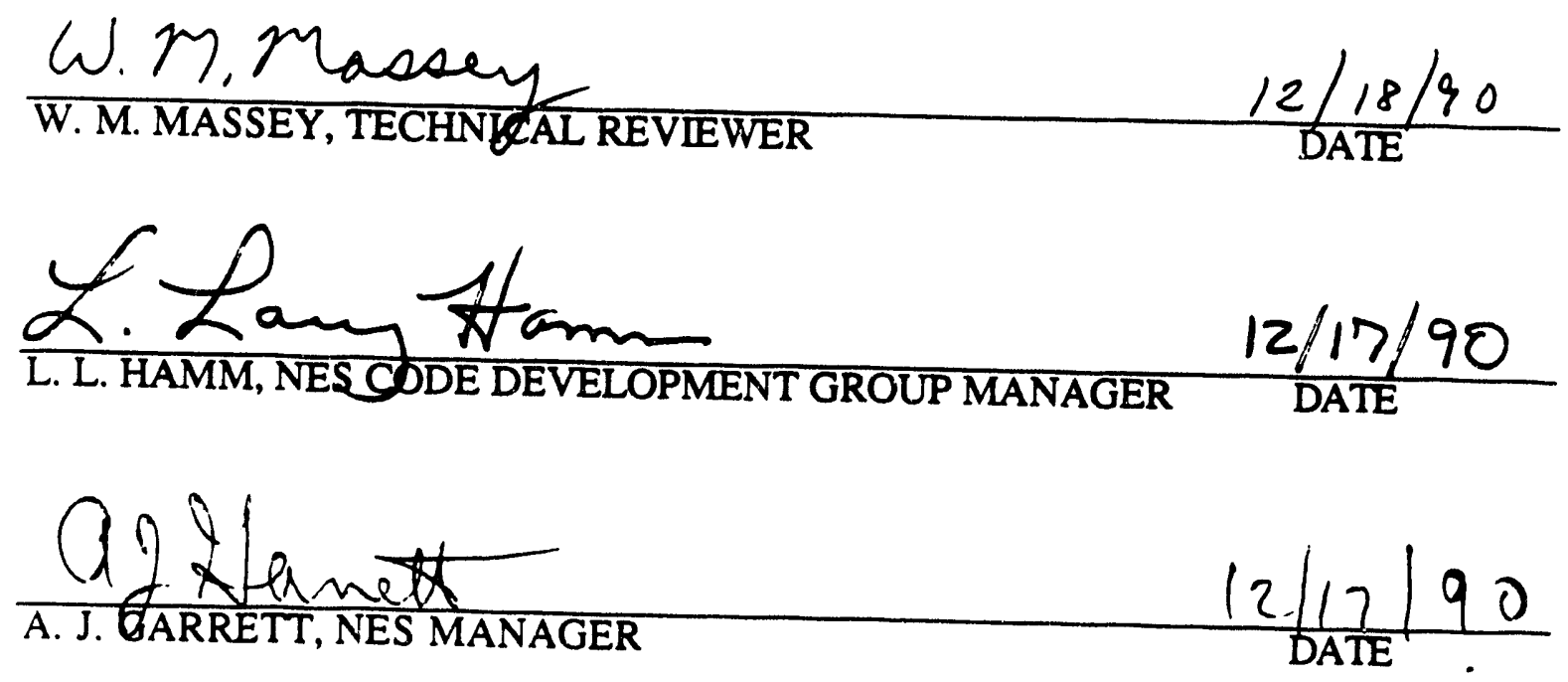


\section{Table of Contents}

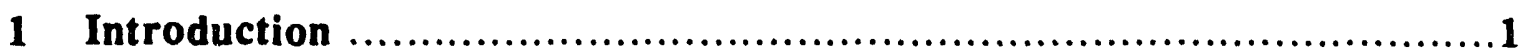

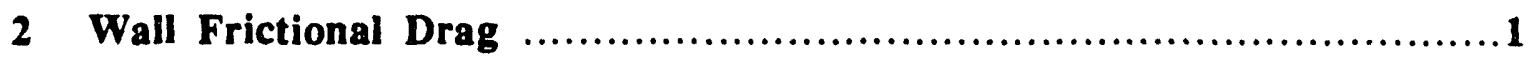

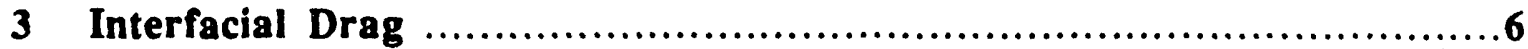

4 Mark-22 Channel Inlet Void Distribution.......................................10

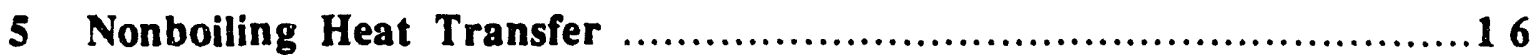

6 Isothermal, Multichannel Integral Benchmarking Results ...............19

6.1 Mark-22 Assembly Total Air Flowrates ...............................19

6.2 Mark-22 Assembly Pressure Profiles .................................2 1

7 Heated, Single Channel Integral Benchmarking Results ................27

$7.1 T_{\text {wall }}=T_{\text {sat }}$ and Onset of Thermal Excursion Powers ...............2 7

7.2 Detailed Temperature Benchmarking Results ......................... 5

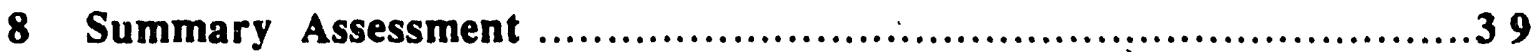

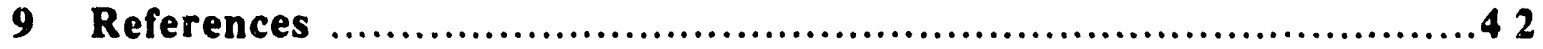




\section{Introduction}

FLOWTRAN-TF is a two-component (air-water), two-phase thermal-hydraulics code designed for performing accident analyses of SRS reactor fuel assemblies during the Emergency Cooling System (ECS) phase of a Double Ended Guillotine Break (DEGB) Loss Of Coolant Accident (LOCA). A description of the code is given by Flach et al. (1990). This report provides henchmarking results for the version of FLOWTRAN-TF used to compute the Recommended K-Reactor Restart ECS Power Limit (Smith et al., 1990a; 1990b). Individual constitutive relations are benchmarked in Sections 2 through 5 while in Sections 6 and 7 integral code benchmarking results are presented. An overall assessment of FLOWTRAN-TF for its intended use in computing the ECS power limit completes the document.

In this document, the term 'benchmark' is used generically to refer to any code prediction and experimental data comparison. Code/data comparisons involving data independent of code development are referred to as 'independent benchmarks'.

\section{Wall Frictional Drag}

The FLOWTRAN-TF wall drag model is described by Flach et al. $(1990, \S 7)$. In this section, we demonstrate that void fraction comparisons under certain conditions can be used to benchmark the frictional component of the wall drag model for two-phase conditions and illustrate such results. The basis for using void fraction comparisons to benchmark the wall frictional drag model under two-phase conditions is as follows. For steady, constant area, axially uniform two-phase flow, the axial mixture momentum balance becomes (Flach et al., 1990, equations (5.4) and (5.5))

$$
0=-\frac{d P}{d z}+\left[\alpha \rho_{g}+(1-\alpha) p_{f}\right] g-F_{w}^{z}
$$

where

$$
\begin{aligned}
\mathrm{P} & \equiv \text { pressure } \\
z & \equiv \text { axial coordinate } \\
\alpha & \equiv \text { void fraction } \\
\rho_{\mathrm{g}} & \equiv \text { gas density } \\
\rho_{\mathrm{f}} & \equiv \text { fluid density } \\
\mathrm{g} & \equiv \text { gravitational constant } \\
F_{w}^{z} & \equiv \text { mixture wall drag }
\end{aligned}
$$

Under pre-CHF conditions, the wall is fully wetted $(\theta=1)$ and the phasic contributions to the mixture wall drag become (Flach et al., 1990, equations (7.2) and (7.3)) 


$$
\begin{gathered}
F_{w g}^{z}=0 \\
F_{w f}^{z}=\frac{1}{2} \frac{\Phi^{z} f_{f}^{z}\left(R e_{f}^{z}\right)}{D_{h}^{z}} \rho_{f} \mid u_{f} / u_{f}
\end{gathered}
$$

where

$$
\operatorname{Re}_{\mathrm{f}}^{z}=\frac{\rho_{\mathrm{f}} / \mathrm{u}_{\mathrm{f}} / D_{h}^{2} K_{h}^{2}}{\mu_{\mathrm{f}}}
$$

and

$$
\begin{aligned}
F_{w_{g}}^{2} & \equiv \text { 'net' wall drag force on gas per unit volume } \\
F_{w f}^{2} & \equiv \text { 'net' wall drag force on fluid per unit volume } \\
\Phi & \equiv \text { LD correction factor } \\
f & \equiv \text { friction factor } \\
D_{h}^{z} & \equiv \text { hydraulic diameter } \\
K_{h}^{z} & \equiv \text { hydraulic diameter correction factor } \\
u_{\mathrm{f}} & \equiv \text { phasic liquid velocity } \\
\mu_{\mathrm{f}} & \equiv \text { liquid viscosity }
\end{aligned}
$$

Since $F_{w}^{z}=F_{w g}^{z}+F_{w f}^{z}$, equation (2.1) becomes

$$
0=-\frac{d P}{d z}+\left[\alpha \rho_{g}+(1-\alpha) \rho_{f}\right] g-\frac{1}{2} \frac{\Phi_{f}^{z} f_{f}^{z}\left(R e_{f}^{z}\right)}{D_{h}^{z}} \rho_{f}\left|u_{f}\right| u_{f}
$$
$\left(\mathrm{j}_{\mathrm{f}}\right.$ ) conditions, void fraction $(\alpha)$ is the sole remaining dependent variable. This implies the FLOWTRAN-TF predicted void fractions by the last term of equation (2.5), defines used to benchmark the model.

Data meeting the above mentioned conditions are available from the VOID Rig (Whatley,
1990 ). Figure 2.1 schematically important flow geometry specifications. standpipe level were all controlled and measured liquid flowrate, inlet pressure and outlet valves, air flowrate and pressures between the quick-closing between the quick-closing Pressures and flowrates were measured every 5 quick-closing valves were also measured. void fractions measured are instantaneous valueconds and averaged over 5 minutes. The state inlet and pressure boundary conditions and. The experiment was run under steady- 
the quick-closing valves was constant. A subset of the database having axially uniform flow conditions was identified through examination of the pressure profile in the test section. A linear pressure profile was taken as an indication of axially uniform flow conditions. Figure 2.3 shows data selected to cover the range of flow conditions of interest in modeling the ECS phase of a DEGB LOCA. A few axially nonuniform data are shown for completeness and to provide a more integral benchmark of the overall momentum model. For a detailed discussion of experimental uncertainties see Whatley (1990). Large scatter in the instantaneous void fraction data was observed for some conditions. Most of the void fraction uncertainty can probably be attributed to real transient variations in void fraction. Based on an inspection of the database in general, a minimum uncertainty in void fraction of \pm 0.01 appears to be reasonable.

The FLOWTRAN-TF computational mesh and input parameters pertaining to channel geometry for the VOID Rig are shown in Figure 2.2. Essentially only the test section between the quick-closing valves is modeled since all the measurements of interest apply to this region. The FLOWTRAN-TF simulations of the VOID Rig experiments were conducted as follows. The inlet (PL) and outlet (TB) boundary cell pressures were iteratively adjusted until the $\mathrm{Ml}$ cell pressure matched the experimental $\mathrm{pb}$ value and the M15 cell pressure matched the pf value. The measured liquid flowrate value was prescribed in the code simulations. None of the VOID Rig data were used to develop the wall frictional drag model.

The FLOWTRAN-TF predicted void fractions are compared to the experimental data in Figure 2.3. The agreement is excellent with the predicted void fraction being essentially within the estimated experimental uncertainty in the data. Based on these benchmark results, we conclude that the FLOWTRAN-TF wall frictional drag model is quite satisfactory and no additional model development is anticipated. 


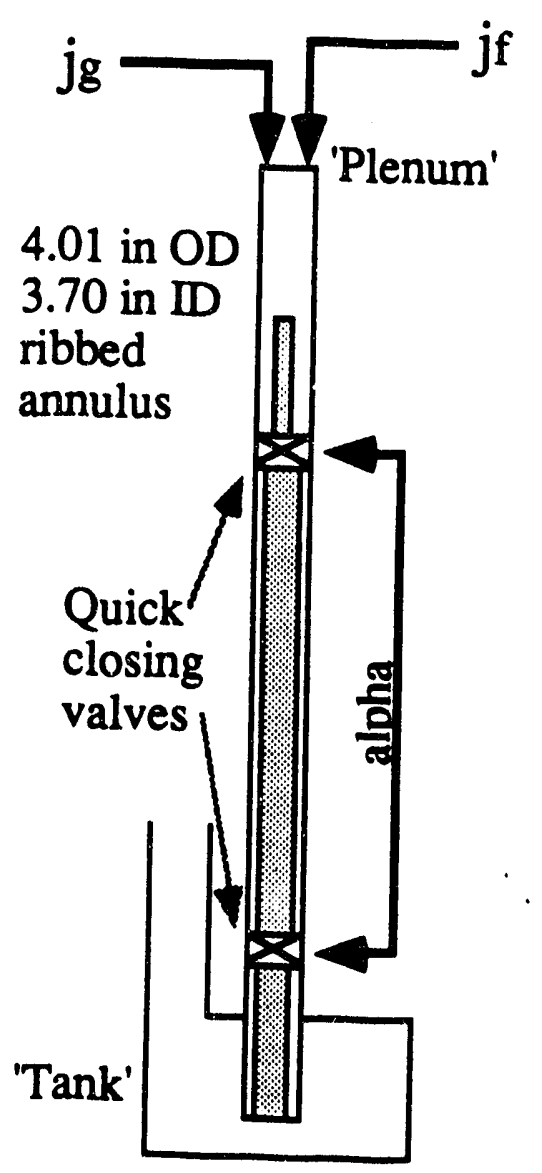

Figure 2.1 Schematic diagram of the VOID Rig 


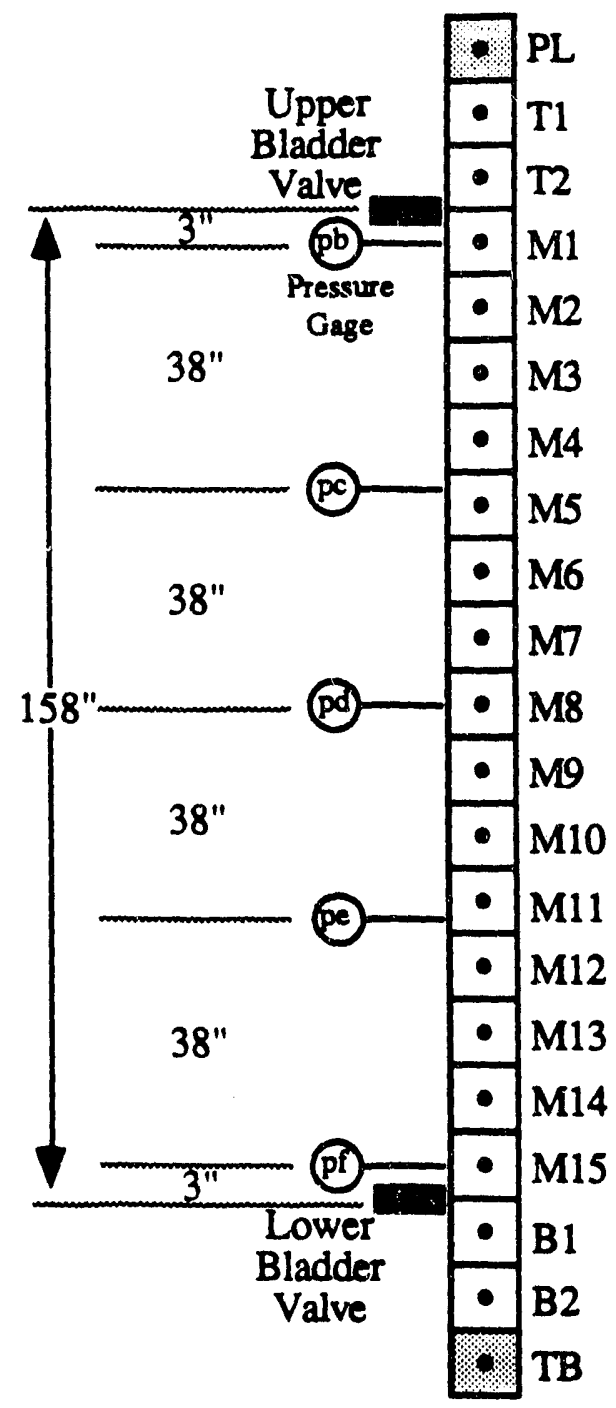

Cell Lengths:

\begin{tabular}{|ccc|}
\hline$\#$ & $\Delta z$ (in) & $\Delta z(m)$ \\
\hline PL-M1 & 6.00 & 0.1524 \\
M2-M14 & 11.26 & 0.2860 \\
M15-TB & 6.00 & 0.1524 \\
\hline
\end{tabular}

Hydraulic Parameters - All Cells:

\begin{tabular}{|c|c|c|}
\hline $\begin{array}{c}\text { Inner } \\
\text { Diameter }\end{array}$ & $\mathrm{D}_{\mathrm{i}}$ & $3.700 \mathrm{in}$ \\
\hline $\begin{array}{c}\text { Outer } \\
\text { Diameter }\end{array}$ & $\mathrm{D}_{\mathrm{o}}$ & $4.010 \mathrm{in}$ \\
\hline Flow Area & $\mathrm{A}_{\mathrm{c}}$ & $1.1902 \times 10^{-3} \mathrm{~m}^{2}$ \\
\hline $\begin{array}{c}\text { Hydraulic } \\
\text { Diameter }\end{array}$ & $\mathrm{D}_{\mathrm{h}}$ & $7.5107 \times 10^{-3} \mathrm{~m}$ \\
\hline $\begin{array}{c}\text { Hydraulic } \\
\text { Diameter } \\
\text { Correction } \\
\text { Factor }\end{array}$ & $\mathrm{K}_{\mathrm{h}}$ & 0.7115 \\
\hline $\begin{array}{c}\text { Interfacia } \\
\text { Drag } \\
\text { Characteristic } \\
\text { Dimension }\end{array}$ & $\mathrm{D}_{\mathrm{c}}$ & $0.156 \mathrm{~m}$ \\
\hline $\begin{array}{c}\text { CCFL } \\
\text { Parameter }\end{array}$ & $\mathrm{m}$ & 0.69 \\
\hline $\begin{array}{c}\text { CCFL } \\
\text { Parameter }\end{array}$ & $\mathrm{C}$ & 0.48 \\
\hline $\begin{array}{c}\text { Absolute } \\
\text { Surface } \\
\text { Roughness }\end{array}$ & $\mathrm{E}$ & $1.524 \times 10^{-6} \mathrm{~m}$ \\
\hline
\end{tabular}

Figure 2.2 FLOWTRAN-TF computational mesh corresponding to the VOID Rig 


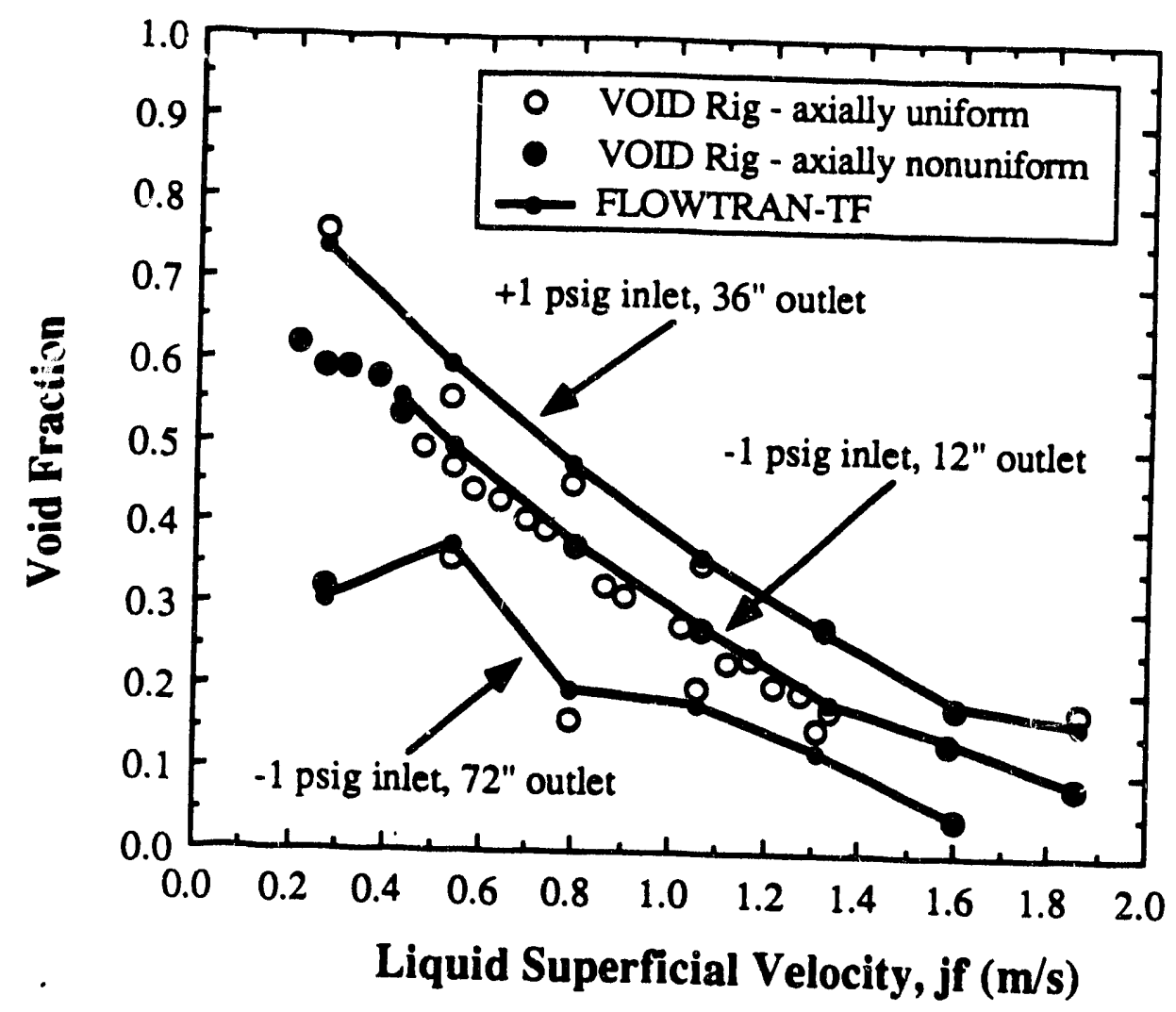

Figure 2.3 Comparison of FLOWTRAN-TF predicted void fraction to VOID Rig
experimental void fraction

\section{Interfacial Drag}

The FLOWTRAN-TF interfacial drag model is described by Flach et al. $(1990, \S 10)$. Some parameters in the model were derived by fitting the model to VOID Rig data for which axially uniform flow occurred. In this section we compare the model to a selected develop the interfacial downflow VOID Rig data. Since much of this data was used to However, the interfacial Flow Distribution (AFD) model is benchmarked in a more integral sense to Annular assembly geometry in Section 6.

The basis for utilizing air flowrate daia to evaluate the interfacial drag model is as follows. For steady, constant area, axially uniform two-phase flow, the gas phase momentum balance becomes (Flach et al., 1990, equation (5.4))

$$
0=-\alpha \frac{d P}{d z}+\alpha \rho_{g} g-F_{w g}^{z}-F_{I}^{z}
$$

where (Flach et al., 1990, equations (10.8))

$$
F_{w g}^{2}=\alpha F_{w}^{z}
$$


and (Flach et al., 1990, equations (10.10))

$$
F_{I}^{2}=C_{I}^{z}\left|u_{T}\right| u_{\mathrm{T}}=\frac{\alpha(1-\alpha)^{3}}{u_{g j}^{2}} \frac{\Delta \rho g}{1-\alpha}\left|\frac{1-C_{0} \alpha}{1-\alpha}-C_{0} u_{f}\right|\left(\frac{1-C_{0} \alpha}{1-\alpha} u_{g}-C_{0} u_{f}\right)
$$

and

$$
\begin{aligned}
P & \equiv \text { pressure } \\
z & \equiv \text { axial coordinate } \\
\alpha & \equiv \text { void fraction } \\
\rho_{g} & \equiv \text { gas density } \\
g & \equiv \text { gravitational constant } \\
F_{w g}^{z} & \equiv \text { net gas wall drag } \\
F_{I}^{z} & \equiv \text { interfacial drag due to relative velocity between the phases } \\
F_{w}^{2} & \equiv \text { mixture wall drag } \\
u_{\mathrm{r}} & \equiv \text { relative velocity } \\
C_{I}^{2} & \equiv \text { interfacial drag coefficient } \\
\Delta \rho & \equiv \rho_{\mathrm{f}}-\rho_{\mathrm{g}} \\
C_{0} & \equiv \text { distribution coefficient } \\
u_{\mathrm{g}} & \equiv \text { gas phasic velocity } \\
u_{\mathrm{f}} & \equiv \text { fluid phasic velocity }
\end{aligned}
$$

For imposed pressure $(\nabla P)$ and liquid flowrate $\left(j_{f}\right)$ conditions, the void fraction $(\alpha)$ is determined by the mixture momentum balance and mixture wall drag model as discussed previously in the Wall Frictional Drag section. Examination of the equation set given by remaining dependent variable. interfacial drag models, gas flowrate is controlled $(3.1-3)$ involve both the wall drag and The wall drag model has been separately fraction data. As previously discussed, the agreement between the FLOWTRAN-TF accurate. If the wall in wrag model is considered to be relatively model indicated by equationstitutive relation is viewed as fixed, then the interfacial drag use air flowrate data from the Vom

The VOID Rig apparatus and corresponding FLOWTRAN-TF computational model are described in Figures 2.1-2 and the accompanying discussion. Figures 3.1 through 3.3 illustrate VOID Rig inlet air flowrate measurements for standard conditions $\left(1\right.$. atm, $\left.25^{\circ} \mathrm{C}\right)$ 
for the same three pressure boundary conditions considered in Figure 2.3. As before the comparison includes a few points for which the axial conditions were not uniform. Whatley (1990) discusses experimental uncertainties in the air flowrate data. In general an uncertainty of $\pm 5 \%$ appears to be reasonable. Some of the data under low gas flowrate conditions probably have a positive bias. Since the air flowrate meters do not distinguish flow direction, an air flow fluctuating about zero net flowrate yields a positive reading. This situation was likely realized during testing since two-phase flows frequently have fluctuations. For example, the data points shown in Figure 3.1 for the liquid superficial velocity range of 0.2 to $0.5 \mathrm{~m} / \mathrm{s}$ appear to have a positive bias; the actual time-averaged superficial velocity is probably zero. Another important observation concerning the data deals with high air flowrate sensitivity to pressure boundary conditions when the pressure gradient is in the vicinity of zero. The data for +1 psig inlet and 36" outlet level is a good example. Figure 3.3 shows only a single data point for each liquid flowrate so the effect is not apparent from this figure. However, Whatley (1990) illustrates much additional data for +1 psig inlet and 36" outlet stardpipe level. Although the pressure boundary conditions are nominally constant, the actual pressure gradient varies slightly between individual data points. Large scatter in air flowrate data is observed indicating a natural sensitivity to the precise pressure gradient. Both of these points should be kept in mind when interpreting the experimental dara.

The FLOWTRAN-TF air flowrate predictions are shown in Figures 3.1-3. These results were obtained using the same procedure described in the Wall Frictional Drag section and in fact were obtained cocurrently with the void fraction predictions. In Figure 3.1 some discrepancy is observed at low liquid flows, however, this appears to be due to data bias as discussed above. FLOWTRAN-TF somewhat overpredicts in the mid-range but otherwise agrees well with the data. In Figure 3.2 the agreement is good. A large discrepancy is seen in Figure 3.3 at the lower liquid flowrates. This is probably due to model deficiency. However, keep in mind that the data exhibits high sensitivity under these conditions so excellent agreement with the data is probably not a reasonable expectation of any interfacial drag model. The overall agreement to the data shown in Figure 3 3.1-3 is considered satisfactory but not excellent. This could partly be anticipated since the model was fit to the data originally. Additional air flowrate comparisons are given in Section 6 for the Mark-22 assembly geometry so we defer making an evaluation of the FLOWTRAN-TF interfacial drag model until after those results have been presented. 


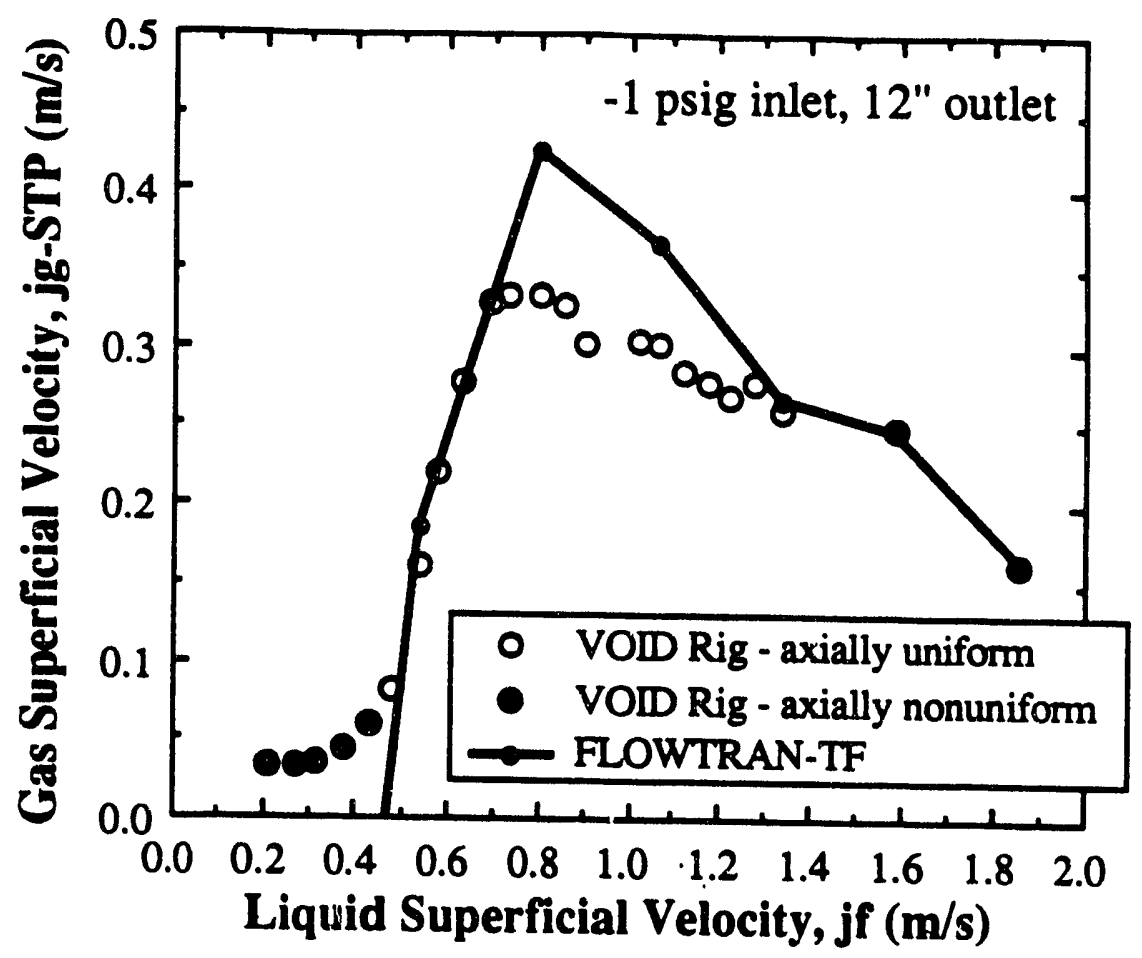

Figure 3.1 Comparison of FLOWTRAN-TF predicted air flowrate to VOID Rig experimental air flowrate for -1 psig inlet pressure and 12" standpipe level

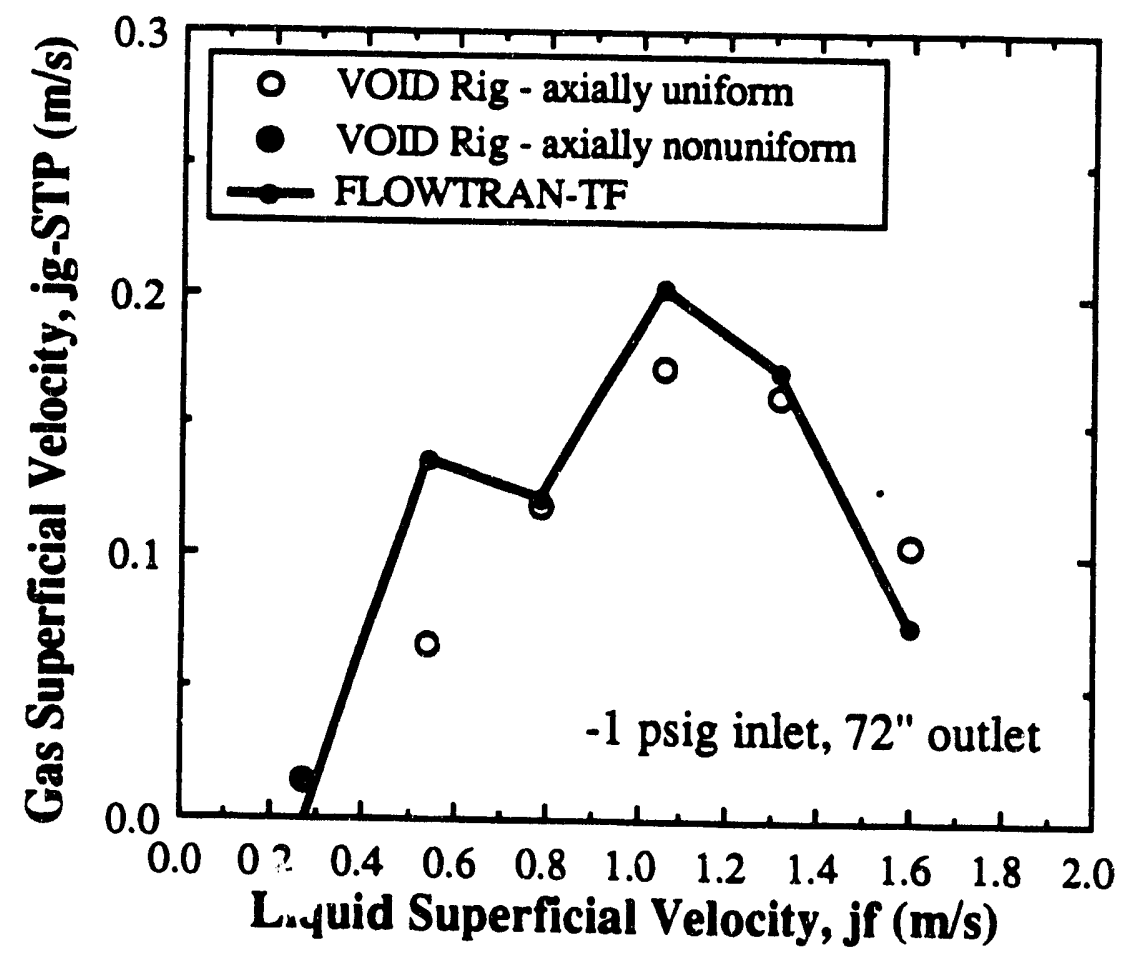

Figure 3.2 Comparison of FLOWTRAN-TF predicted air flowrate to VOID Rig experimental air flowrate for -1 psig inlet pressure and 72 "standpipe level 


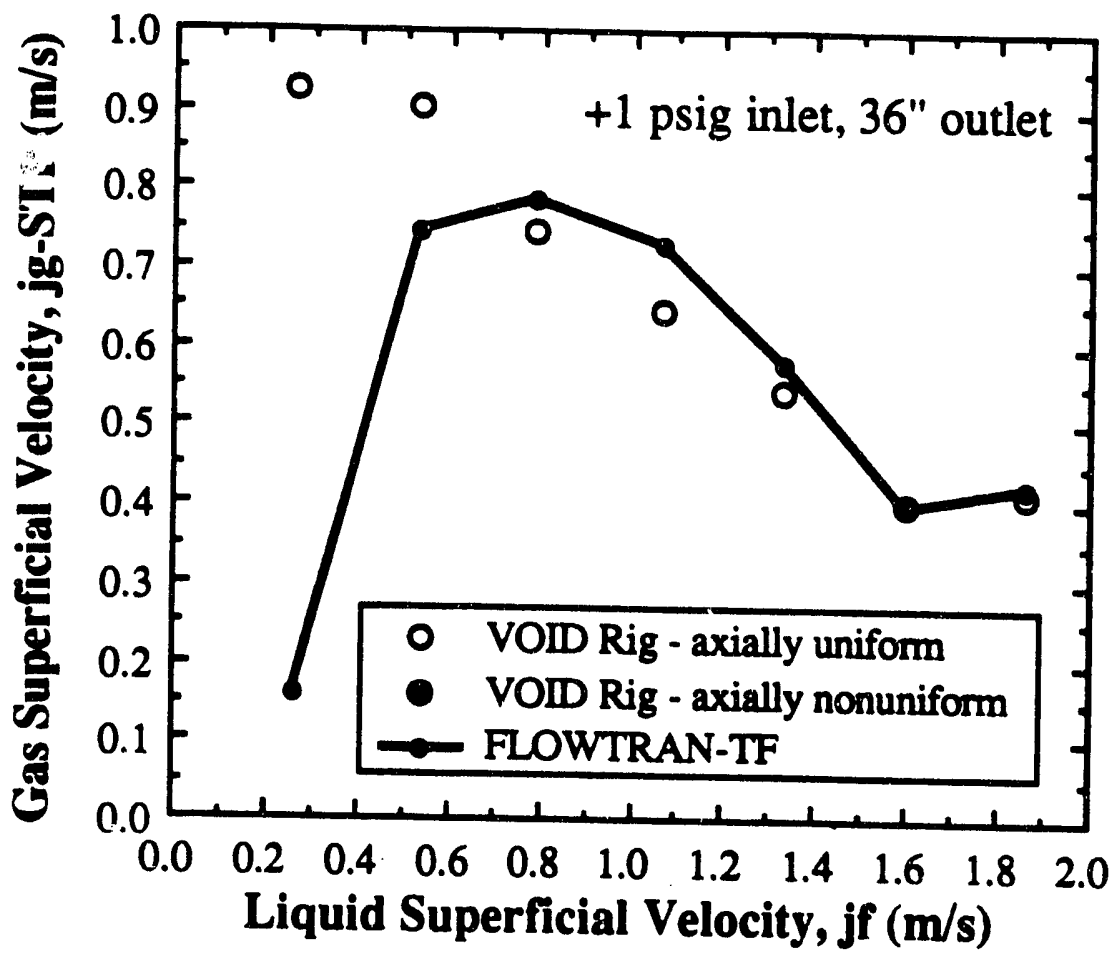

Figure 3.3 Comparison of FLOWTRAN-TF predicted air flowrate to VOID Rig experimental air flowrate for +1 psig inlet pressure and 36 " standpipe level

\section{Mark-22 Channel Inlet Void Distribution}

Two-phase separation generally occurs at the dividing junction between a single channel and multiple channels. This situation is encountered in a Mark-22 assembly as the flow enters the active core region as shown in Fig. 4.1. As discussed in the FLOWTRAN-TF Code Description document (Flach et al., 1990, \$11), the local void fraction at the multichannel entrances is not generally equal to the upstream average void fraction. Since, the channel inlet void distribution has a major impact on the overall assembly flow behavior, an empirical model was developed from prototypic Mark-22 data to capture this phenomenon. FLOWTRAN-TF completeness, we summarize the model below.

For $\Delta \mathrm{P}<0 \mathrm{~Pa}$ (adverse pressure gradient), the inner and middle channel inlet void fractions are computed from (Flach et al., 1990, equations (11.4) and (11.5))

$$
\begin{aligned}
& \alpha_{i}^{\text {adv }}=0.3088 \alpha-0.3106 \alpha^{2}+4.4771 \alpha^{3}-7.4838 \alpha^{4}+4.0085 \alpha^{5} \\
& \alpha_{m}^{\text {adv }}=0.9292 \alpha-1.9320 \alpha^{2}+9.9311 \alpha^{3}-12.783 \alpha^{4}+4.8547 \alpha^{5}
\end{aligned}
$$

For $\Delta \mathrm{P}>\Delta \mathrm{P}_{0}=200 \mathrm{~Pa}$ (favorable pressure gradient), the correlations are (Flach et al.,
1990 , equations (11.6) and (11.7)) 


$$
\begin{gathered}
\alpha_{i}^{\mathrm{fav}}=\alpha-2.2029 \alpha^{2}+4.2057 \alpha^{3}-2.0028 \alpha^{4} \\
\alpha_{\mathrm{m}}^{\mathrm{fav}}=\alpha-2.5932 \alpha^{2}+14.667 \alpha^{3}-21.131 \alpha^{4}+9.0472 \alpha^{5}
\end{gathered}
$$

In equations (4.1-4) $\alpha$ denotes the upstream cell average void fraction. The pressure difference $\Delta P$ is defined to be the upstream cell pressure minus the arithmetic average of the cell pressures in the middle section at the top axial layer. In the pressure gradient transition region, $0<\Delta \mathrm{P}<\Delta \mathrm{P}_{0}$, linear weighting between the adverse and favorable correlations defines the channel inlet void distribution as (Flach et al., 1990, equation (11.8))

$$
\alpha_{k}=\left(1-\frac{\Delta P}{\Delta P_{0}}\right) \alpha_{k}^{\text {adv }}+\left(\frac{\Delta P}{\Delta P_{0}}\right) \alpha_{k}^{\text {fav }}
$$

Finally, the outer channel inlet void fraction computed from the mass balance (Flach et al., 1990 , equation (11.3))

$$
\alpha=\sum_{k=1, m, 0} \alpha_{k} \frac{V_{k}}{V}=\sum_{k=1, m, 0} \alpha_{k} \frac{A_{k}}{A}
$$

where $A_{k}$ is the inlet flow area of the kth channel and $A=\Sigma A_{k}$.

The correlations were derived from Annular Flow Distribution (AFD) experiment (Childerson et al., 1990) liquid flow fraction data. Figure 4.2 schematically illustrates the basic concept behind the experiment and the data measured. The Reference Rig is fully prototypic while the Test Rig deviates from the Mark-22 geometry below the middle section channel exits with the individual channel flows being kept separate to enable flow measurements. The liquid flow fraction data was taken in the Test Rig. The Reference Rig was run in conjunction with the Test Rig to ensure the Test Rig two-phase flow conditions were prototypic. Detailed pressure measurements were taken in both rigs. If the pressure readings from both rigs matched to within a given tolerance, the rigs were said to be hydraulically similar and flow fraction results from the Test rig were accepted.

The adverse pressure gradient correlations are based on fitting 45 data points inferred from Annular Flow Distribution (AFD) experimental data (Childerson et al., 1990) while 9 points were used to derive the favorable pressure gradient correlations. The model was developed while the AFD experiments were in progress. Consequently, additional data which became available after model developement are available for independent benchmarking of the model given by equations $(4.1-6)$. We take channel liquid flow fraction comparisons as our measure for the performance of the Mark-22 channel inlet void distribution model. Such results are shown in Figs. 4.3 and 4.4 where FLOWTRAN-TF predictions of middle and inner channel liquid flow fraction are compared to AFD experimental data. Virtually all of the AFD two-phase data given in Childerson et al. (1990) is included in Figs. 4.3-4 with 72 points shown. Additional AFD experimental data has recently been reported by Kielpinski (1990). The comparisons include both data used to generate the correlations (4.1-4) and the additional, independent data. Figures 4.5 and 4.6 illustrate much of the same benchmarking results in Figs. 4.3-4 but with the various assembly pressure drops identified. These figures include 51 of the 72 individual comparisons shown in Figs. 4.3 and 4.4. Here dp is defined as the inlet minus outlet pressure difference. 
From these benchmarking results, we find that FLOWTRAN-TF can predict the correct liquid flow into each of the three major annular channels of the Mark-22 under a variety of boundary conditions using the present channel inlet void distribution model.

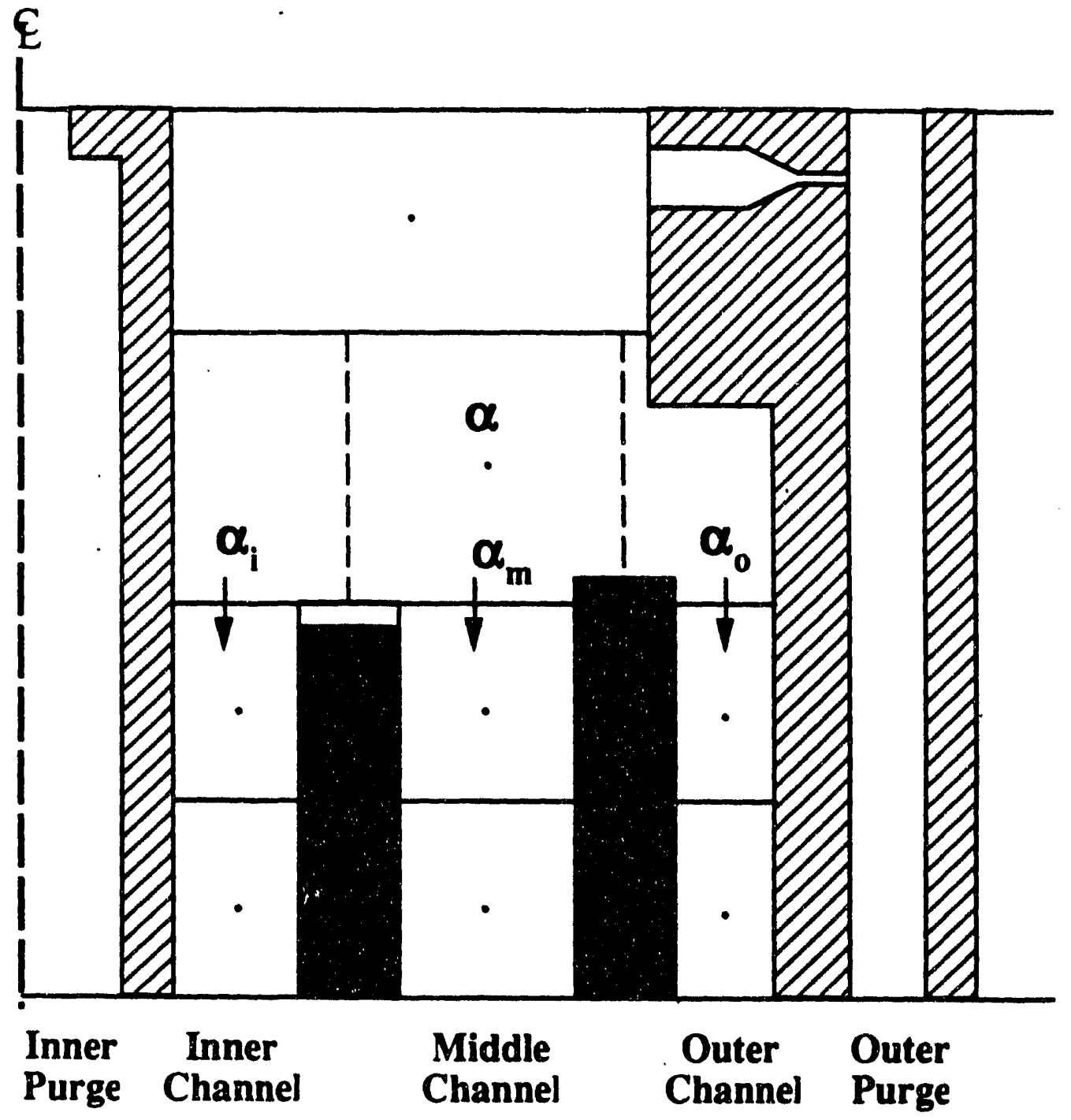

Figure 4.1 Schematic diagram of Mark-22 assembly geometry and FLOWTRAN-TF nodalization (axisymmetric view) 


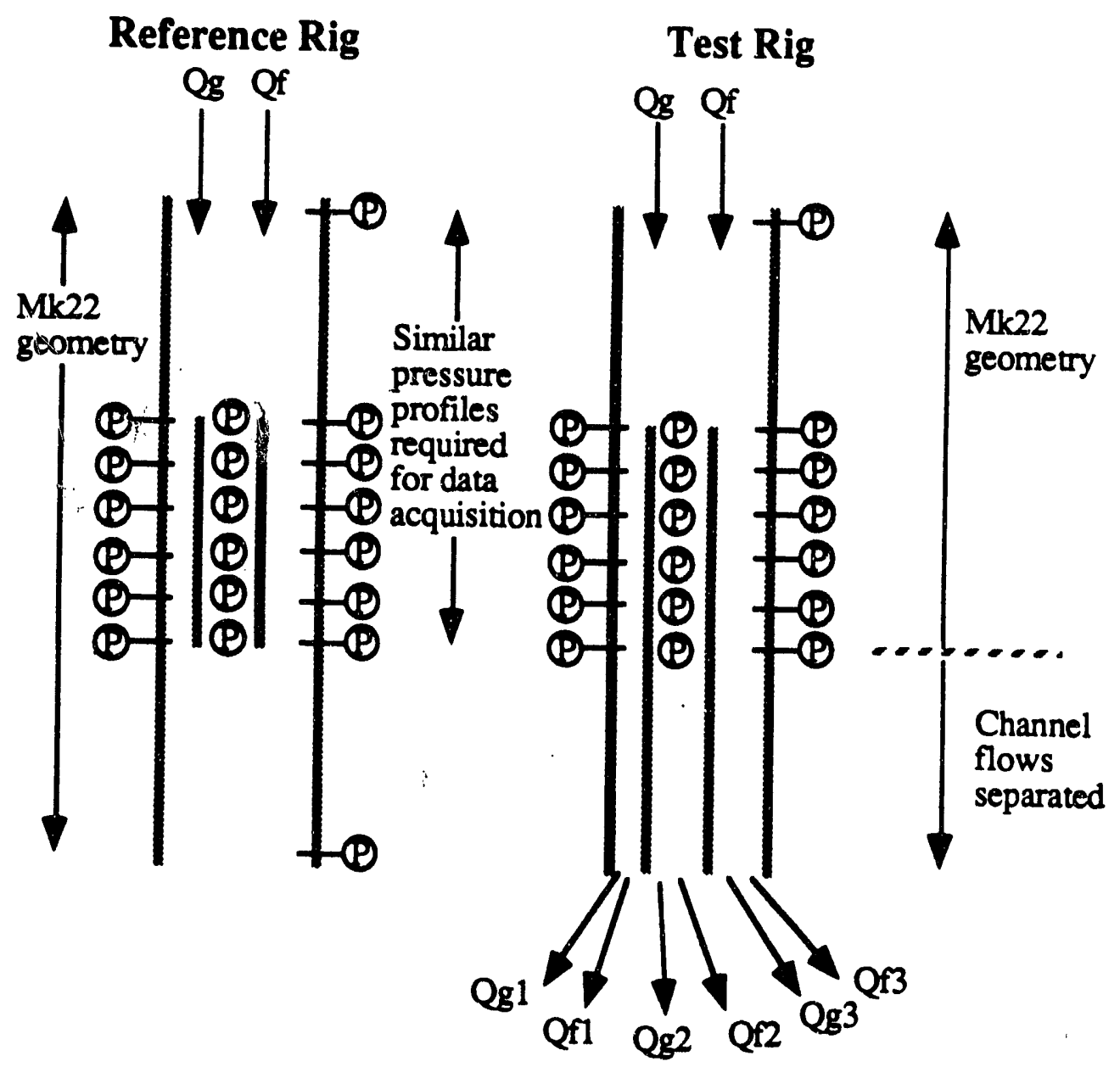

Figure 4.2 Schematic diagram of Annular Flow Distribution (AFD) experiment. 


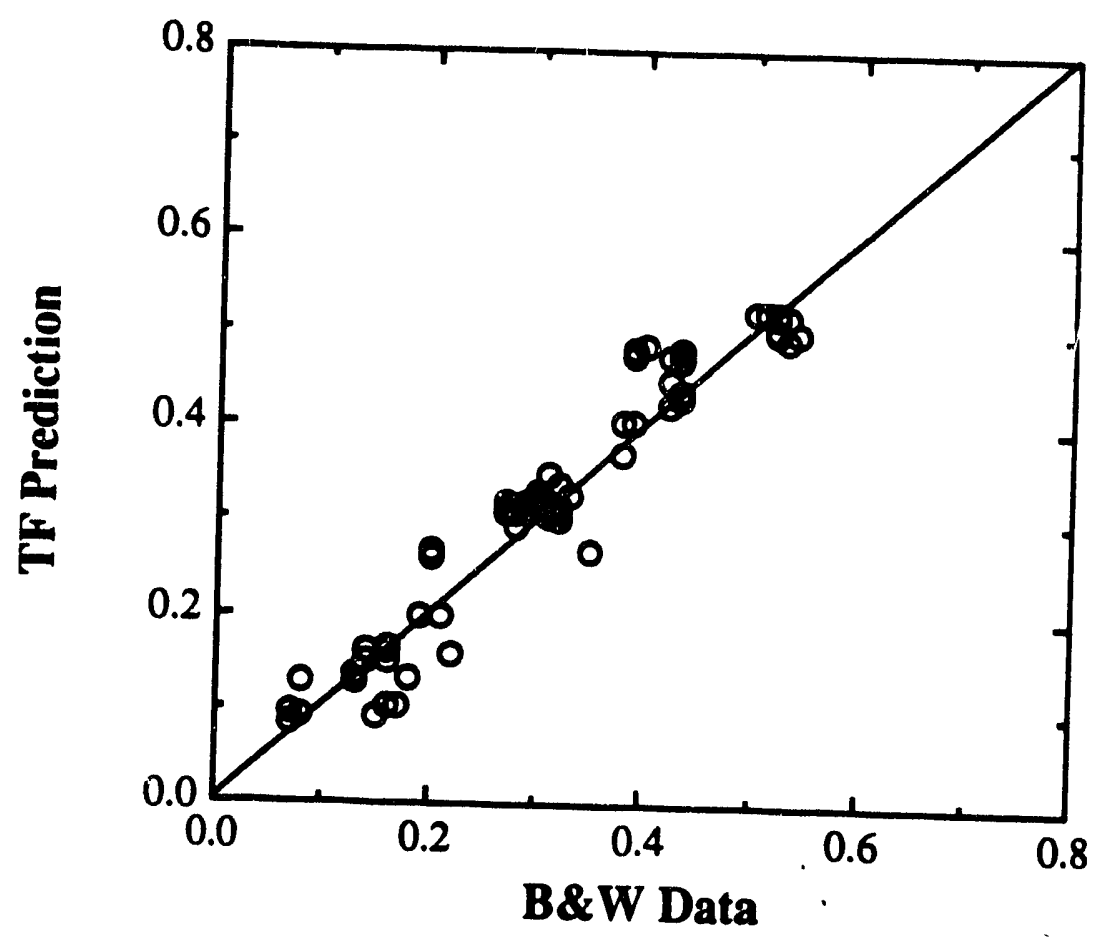

Figure 4.3 Overall comparison of FLOWTRAN-TF predictions of middle channel
liquid flow fraction with AFD data

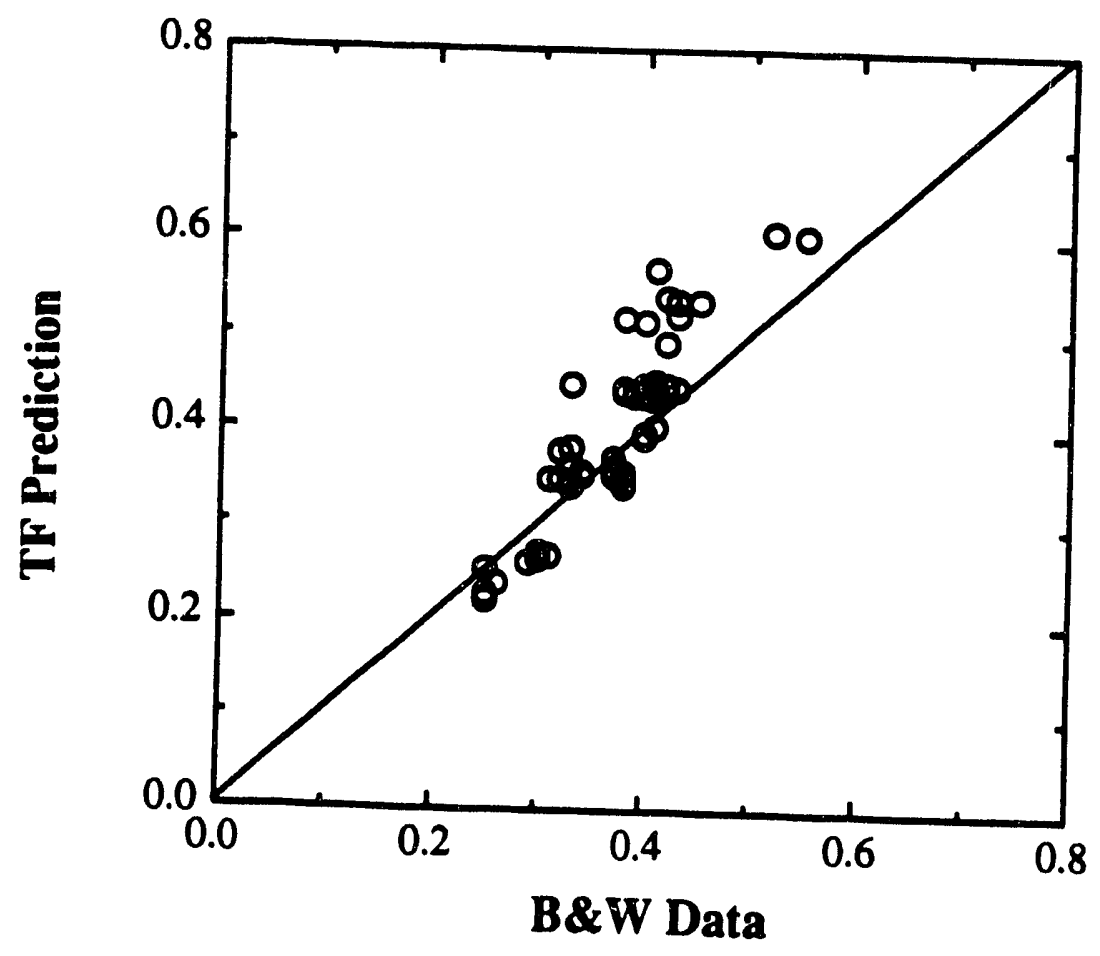

Figure 4.4 Overall comparison of FLOWTRAN-TF predictions of inner channel liquid
flow fraction with AFD data 


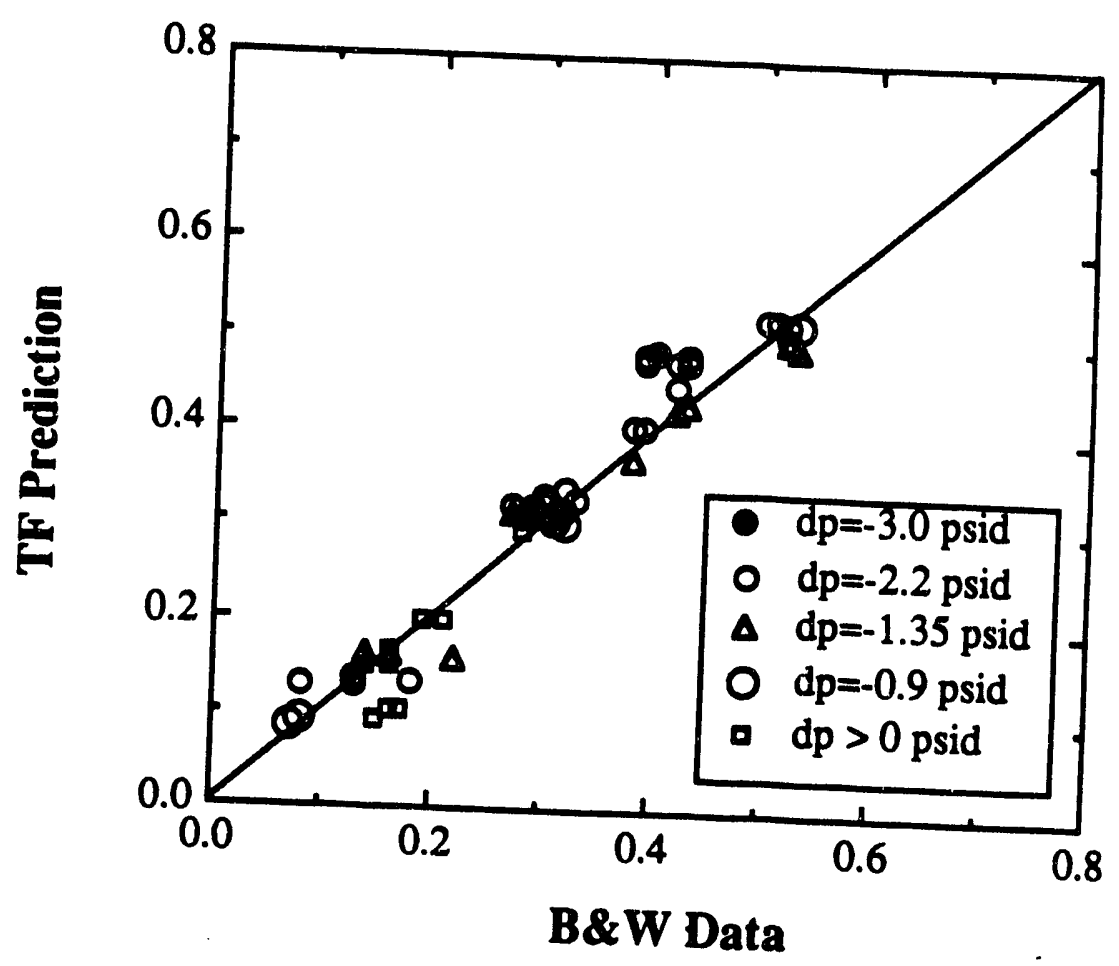
Figure 4.5 Comparison of FLOWTRAN-TF code predictions of middle channel liquid
flow fraction with AFD data for various assembly pressure drops

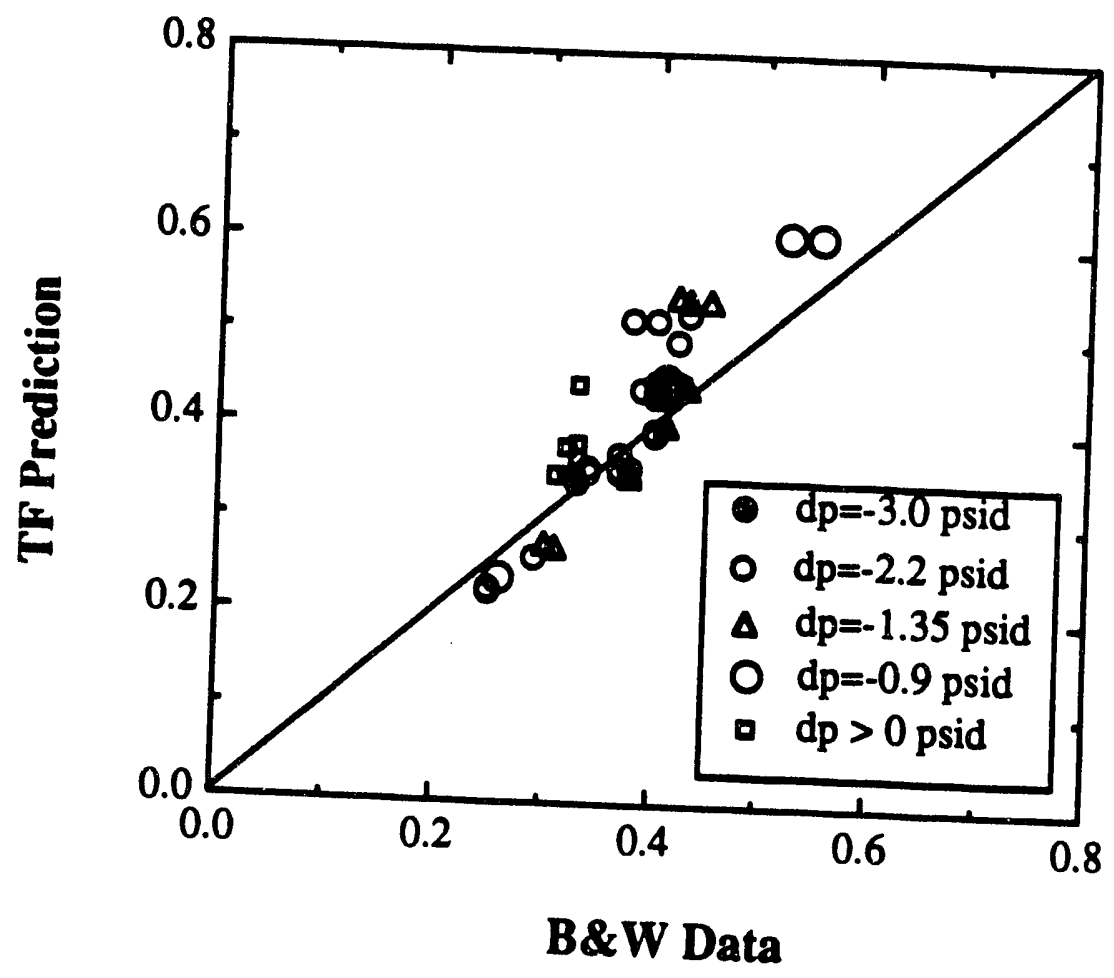
Figure 4.6 Comparison of FLOWTRAN-TF code predictions of inner channel liquid
flow fraction with AFD data for various assembly pressure drops 


\section{Nonboiling Heat Transfer}

Correlations suitable for air-water downflow in ribbed annuli were developed using experimental data obtained from Rig B (Guerrero, 1990) at SRS as discussed by Flach et al. (1990, §6). No new additional data is available for independently benchmarking these correlations. In this section, we repeat the data and correlation comparisons contained in the report by Flach et al. $(1990, \$ 6)$ for completeness and assess the performance of the correlations. The comparisons are shown in Figs. 5.1-3. The data correlations are based on channel averaged metal temperatures corrected for azimuthal peaking and on fluid temperatures calculated from the inlet temperature and the power applied to the rig assuming a uniform heater. In general, metal temperatures on the outer wall of the heater were measured at thirteen axial levels and azimuthally at the centers of the four subchannels. The middle eleven thermocouple positions were used in the data analysis. The four azimuthal temperature measurements at these axial positions were averaged and the corresponding inner surface temperature calculated using a one dimensional heat conduction calculation. At two axial levels, eight thermocouples were positioned across a single subchannel. The azimuthal peaking correction was then based on the observation that metal temperatures measured at the middle of the subchannel were 1 to $5^{\circ} \mathrm{C}$ higher than the average. A separate correction was made for each experiment. Void fractions, used to obtain phasic liquid velocities, were obtained from FLOWTRAN-TF calculations. The code calculation of channel void is not significantly altered by the heat transfer and so the computation can be performed with estimated heat transfer coefficients.

In general the data exhibits large scatter about the correlations as can be seen from Figs. 5.1 and 5.3. Some trend is apparent in the $8 \mathrm{gpm}$ data as a function of pressure difference across the assembly. The $8 \mathrm{gpm}$ data taken with a positive pressure gradient falls below the overall best fit correlation while data at the two most negative pressure gradients fall above the correlation and show a somewhat different slope. However, the results from an uncertainty analysis for the dispersed regime data, which are shown in Fig. 5.2, suggest the scatter is largely due to experimental error rather than model deficiency. Rig-B was not originally intended nor designed for obtaining accurate heat transfer coefficient data so this is not surprising. Given the probable large data uncertainty, we view these two-phase forced convection heat transfer correlations for the dispersed and annular flow regimes as preliminary estimates that will be revised when a better data base becomes available. Work at SRS is currently in progress to obtain more prototypic heat transfer data for air-water downflow in an annular geometry.

A surprising finding was that the data correlations in Figs. 5.1 and 5.3 were not improved by including some function of the gas flow rate since it is expected that air flow would influence the local heat transfer. Several attempts to include such functionality in the correlation were made without improving the fit to the experimental data. The gas flow is included only indirectly since a phasic liquid velocity is used in the dispersed flow correlation. Nevertheless, the correlations represent data with downflow of air and water in a ribbed annulus with dimensions prototypic of an SRS reactor assembly channel. The uniform stainless steel heater in Rig B provided a well characterized solid so that inner wall temperatures could be calculated with good confidence from the measured outer wall values. The data base also covers boundary conditions expected to occur in an assembly channel during the ECS phase of a DEGB LOCA. Therefore, we have chosen to use the heat transfer correlations derived from the SRS data in our limits calculations. 


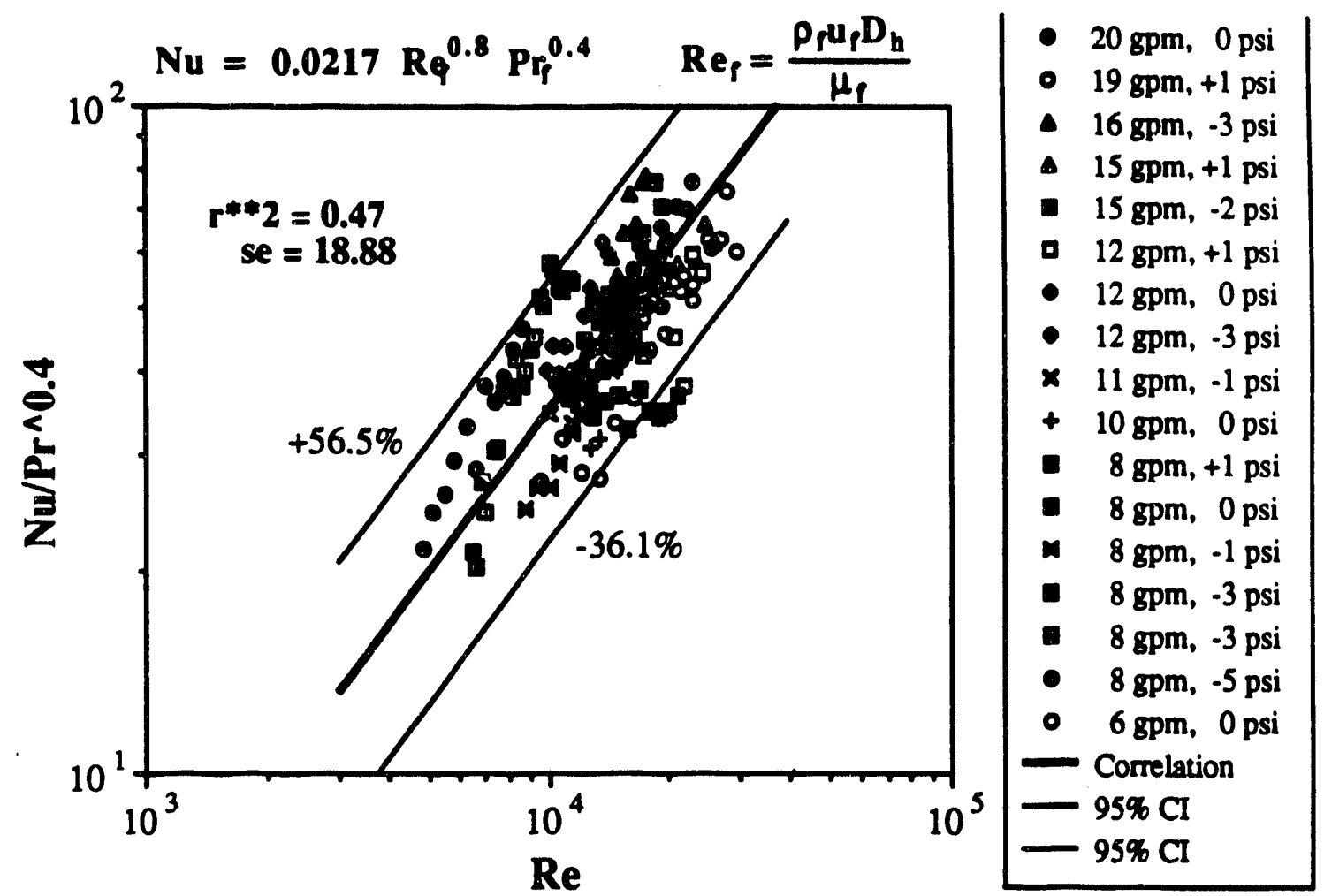

Figure 5.1 Correlation of Rig-B dispersed regime heat transfer data

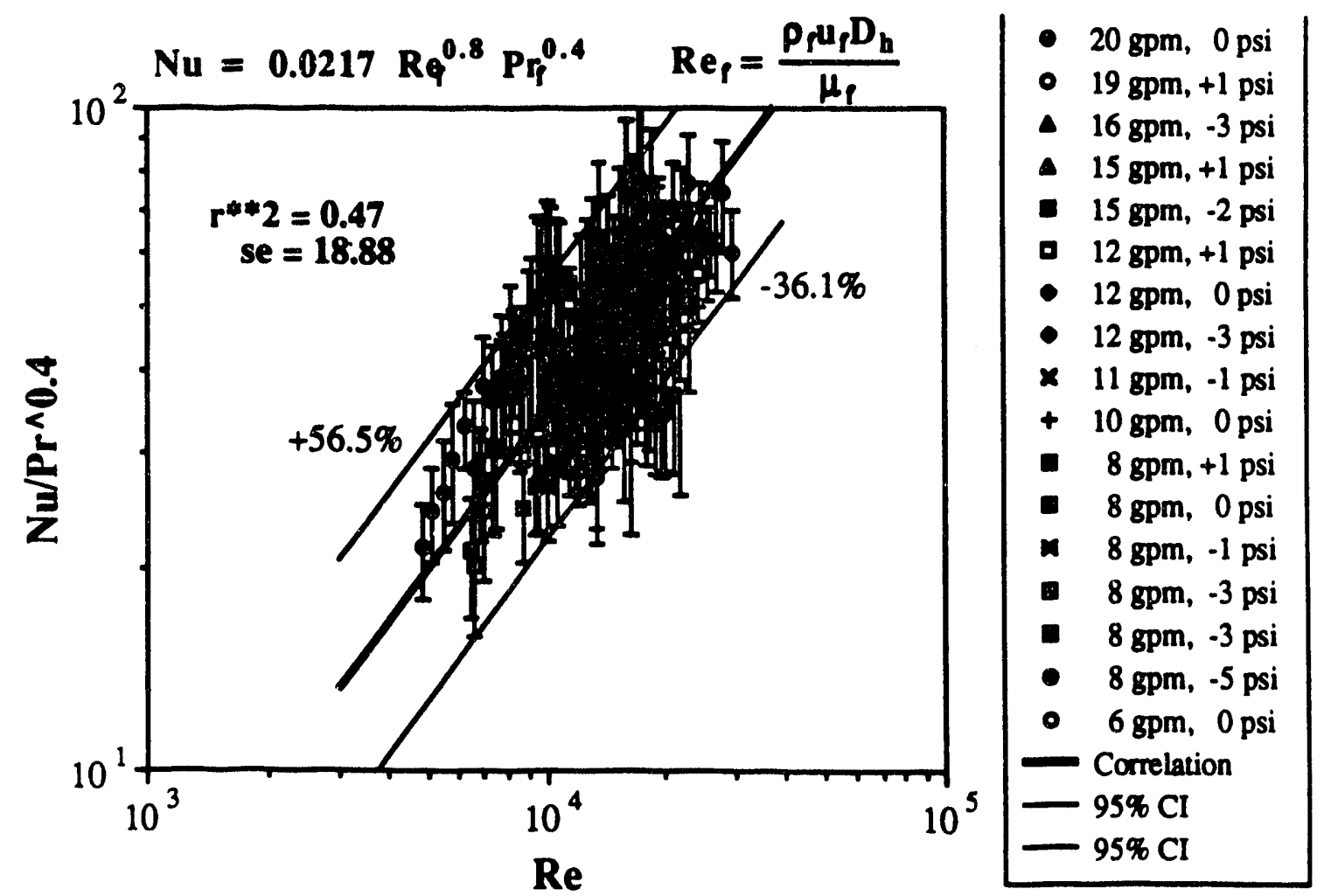

Figure 5.2 Rig-B heat transfer data with experimental error bars shown (dispersed regime) 


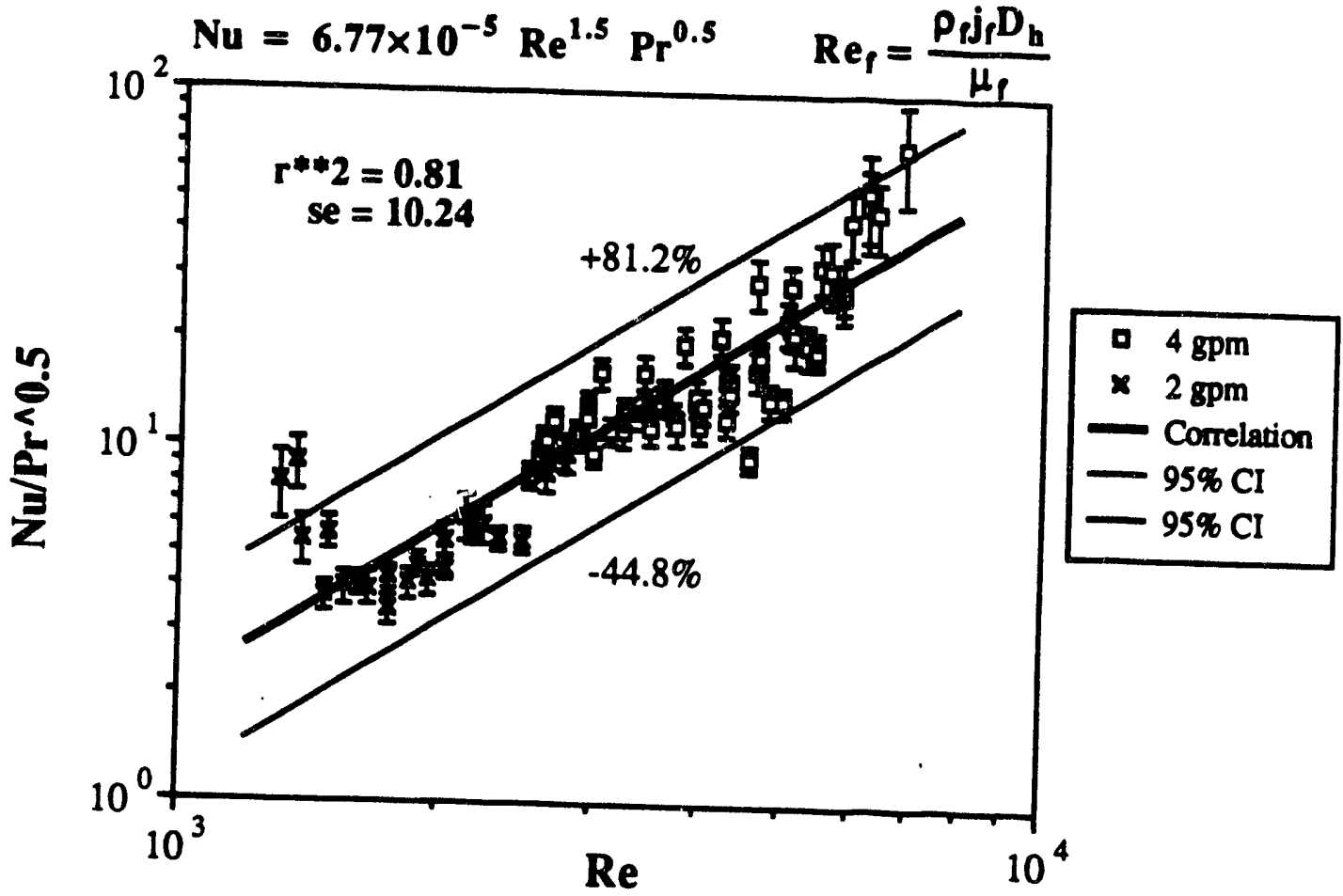

Figure 5.3 Correlation of Rig B annular regime heat transfer data 


\section{Isothermal, Multichannel Integral Benchmarking Results}

In this section we present benchmarking comparisons involving the Annular Flow Distribution (AFD) isothermal experimental data taken from a prototypic Mark-22 assembly geometry (Childerson et al., 1990). Total assembly air flowrate and pressure profile benchmarking results are given. All experimental data is taken from the fully prototypic Reference Rig shown in Fig. 4.2.

\subsection{Mark-22 Assembly Total Air Flowrates}

Total assembly air flowrate comparisons are viewed as an integral test of the overall FLOWTRAN-TF momentum model. Figure 6.1 illustrates total assembly air flow benchmarking results for 67 separate tests for which the measured airflow is nonzero. Figure 6.2 breaks out a subset of these results to show typical air flow behavior as a function of liquid flowrate and assembly pressure pressure difference. At high air flowrates the agreement is reasonable but the code tends to underpredict. At lower airflow rates FLOWTRAN-TF substantially overpredicts (note the log scale). The degree of discrepancy for these benchmarking results is surprising. The single-channel air flow comparisons diccussed in Section 3 are much better. Although the interfacial drag model was developed by fiting the VOID Rig data, we anticipated the Mark-22 comparisons to be similar since the channel geometries are similar. The precise explanation for the poor Mark-22 air flow benchmarking results is not clear.

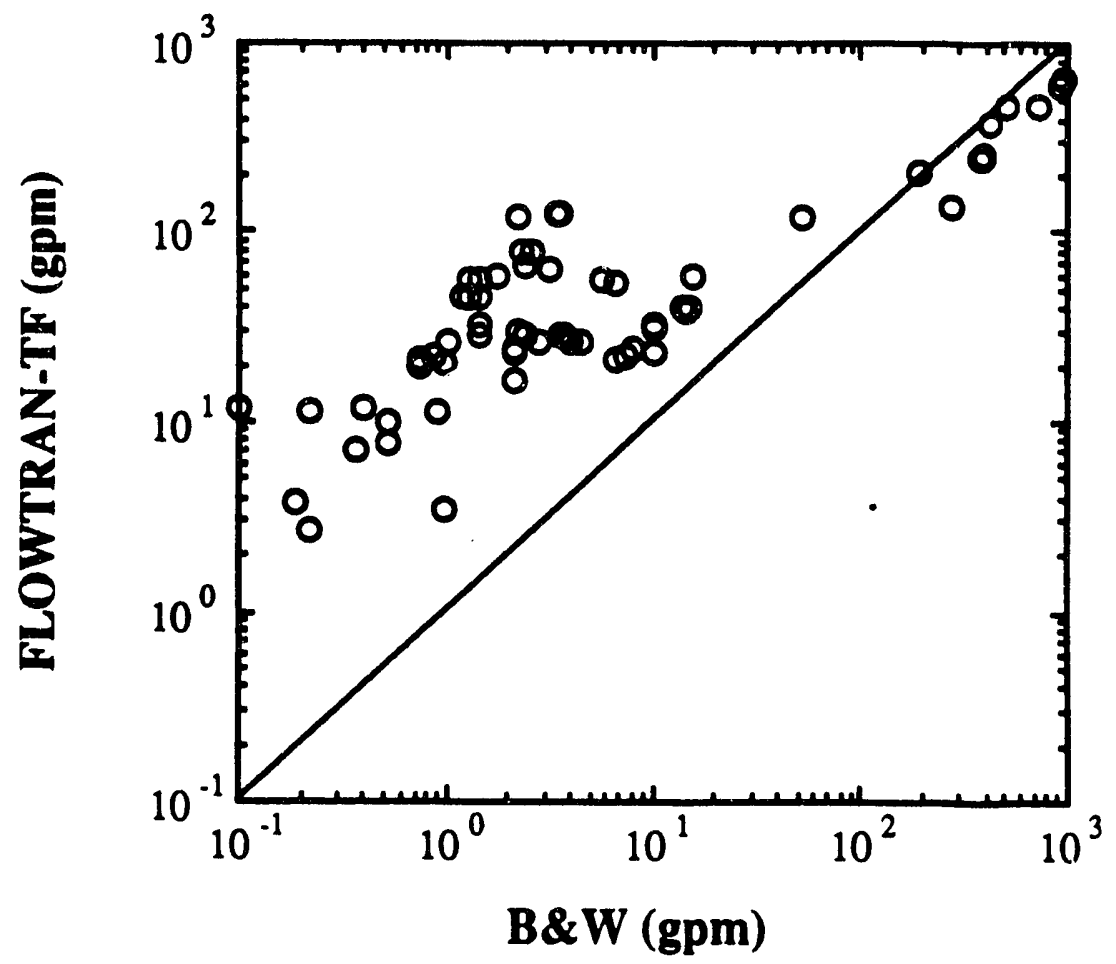

Figure 6.1 Comparison of predicted assembly air flowrates with AFD experimental data 


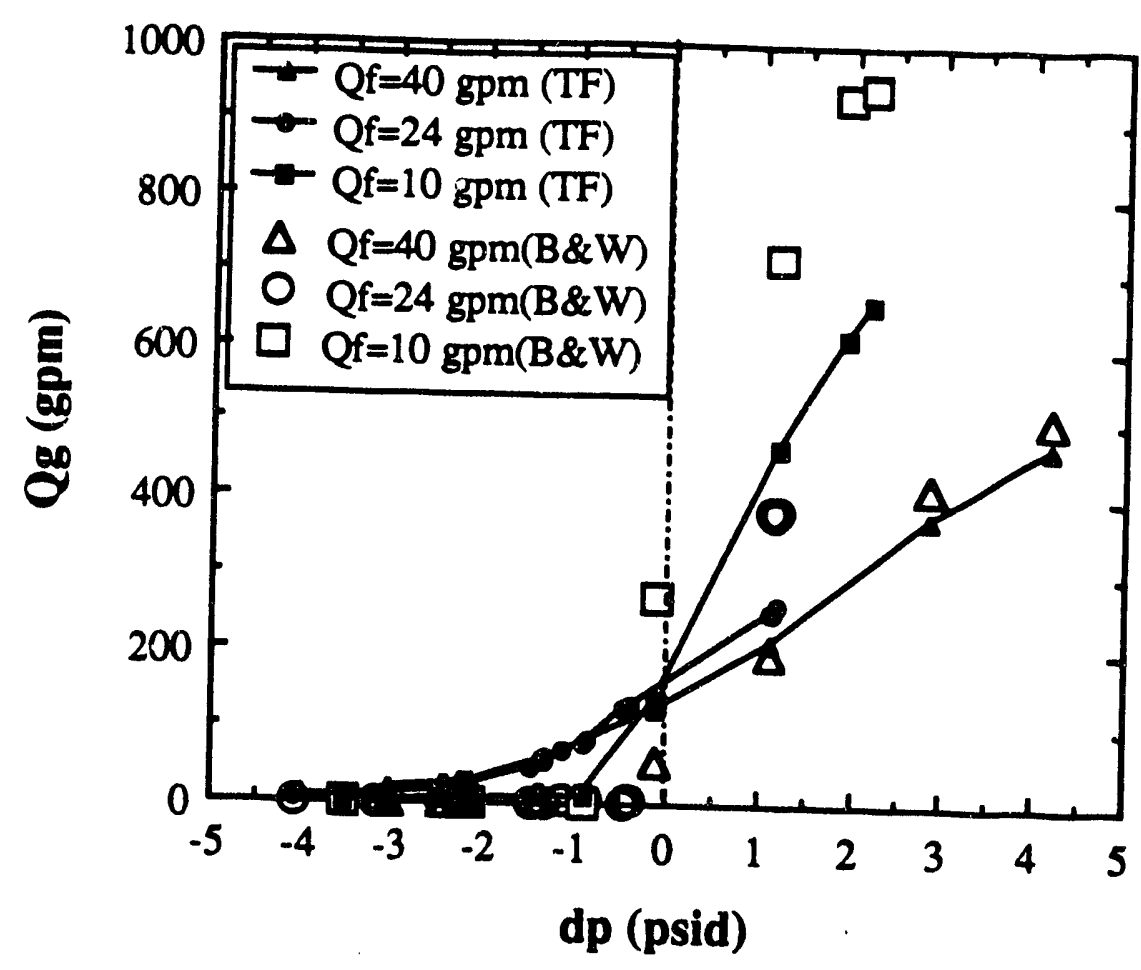

Figure 6.2a Comparison of predicted assembly air flowrate with AFD data for selected conditions; $0-1000 \mathrm{gpm}$ scale (dp $\equiv$ pressure difference between inlet
plenum and tank bottom)

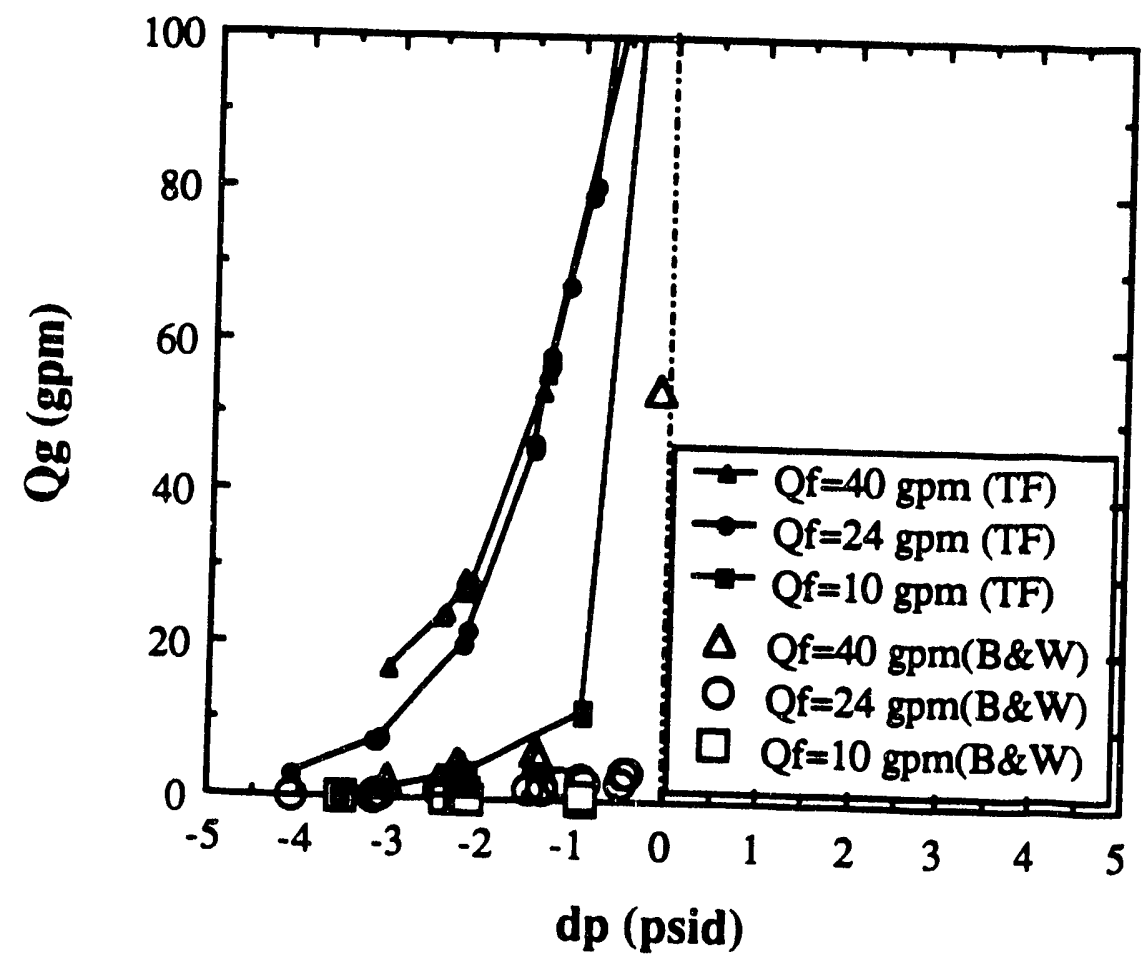

Figure 6.2b Comparison of predicted assembly air flowrate with AFD data for selected conditions; $0-100 \mathrm{gpm}$ scale (dp $\equiv$ pressure difference between inlet plenum 


\subsection{Mark-22 Assembly Pressure Profiles}

Another integral benchmark involving the overall momentum model is a comparison of pressure profiles in the Mark-22 assembly. First, predicted pressure profiles for the Middle Section of the Mark-22 geometry are compared to the AFD measured profiles in the Reference Assembly shown schematically in Fig. 4.2. Then, comparisons of pressure drop across the Bottom Fitting Insert (BFI) are shown. For reference, Fig. 6.3 illustrates the FLOWTRAN-TF fluid computational mesh for the Middle Section and shows the pressure tap locations for the AFD Reference Assembly.

Figures 6.4 through 6.9 compare the pressure profiles predicted by FLOWTRAN-TF with AFD experimental data for various liquid flow rates and assembly pressure differences. The results are for three liquid flowrates at two different pressure boundary conditions each. In these figures, ' $d p^{\prime}$ is defined as inlet plenum pressure minus tank bottom pressure. The symbols 'pi', 'pm', and 'po' denote the local azimuthally-averaged pressure for the inner, middle and outer channel, respectively. The $\mathrm{z}$ coordinate is directed upward in the opposite direction of the downward liquid flow. Linear pressure profiles correspond to axially uniform flow conditions since the flow areas are constant in the Middle Section. Nonlinear profiles indicate a void fraction variation.

Figure 6.4 illustrates benchmarking results for a liquid flow of about $10 \mathrm{gpm}$ and a nearly zero assembly pressure difference. The predicted and measured pressure profiles are both linear and the pressure differences across the Middle Section differ by a few tenths of a psi. Similar results are shown in Fig. 6.6 for approximately $24 \mathrm{gpm}$ of liquid flow. In Fig. 6.7 the profiles are again linear but show a large gradient corresponding to low void. The agreement is excellent but not surprising since this case is not far removed from single phase flow. The form loss coefficients in the FLOWTRAN-TF model were calibrated against single phase data and the frictional wall drag is quite accurate as described in Section 2. Figure 6.8 also shows linear profiles with significant gradients for all channels. Note that the pressure gradients differ in sign from those just discussed and imply relatively high channel void fractions. The code predictions substantially agree with the data.

Nonlinear FLOWTRAN-TF profiles are shown in Fig. 6.5 for the middle and outer channels. Fo: these channels, the upper portion is in a high void annular (falling film) regime with an open gas core and the pressure gradient is essentially zero. The lower portion contains a dispersed regime and all of the overall channel pressure difference occurs here. For the profiles in Fig. 6.5, the pressure gradient in the lower portion of the middle and outer channels corresponds to essentially a solid water leg in agreement with the data. The inner channel FLOWTRAN-TF result indicates an axially uniform dispersed flow regime. However, the experimental profile for the inner channel is nonlinear and implies a spatial flow regime transition from annular to dispersed.

Pressure difference comparisons across the Bottom Fitting Insert are shown in Fig. 6.10 for several representative flow conditions. These benchmarking results largely test the performance of the FLOWTRAN-TF form loss model since frictional losses are small across the BFI. The agreement between predicted and experimental results is quite good. The excellent benchmarking results may be partly due to the geometry involved. Since, the BFI geometry contains pressure plates perforated with orifice holes, the t wo-phase flow is thought to be relatively homogeneous. The FLOWTRAN-TF form loss model is an extension of the homogeneous flow model and reduces to the homogeneous model under no slip conditions. Hence, FLOWTRAN-TF form loss model is well suited to modeling the BFI. 


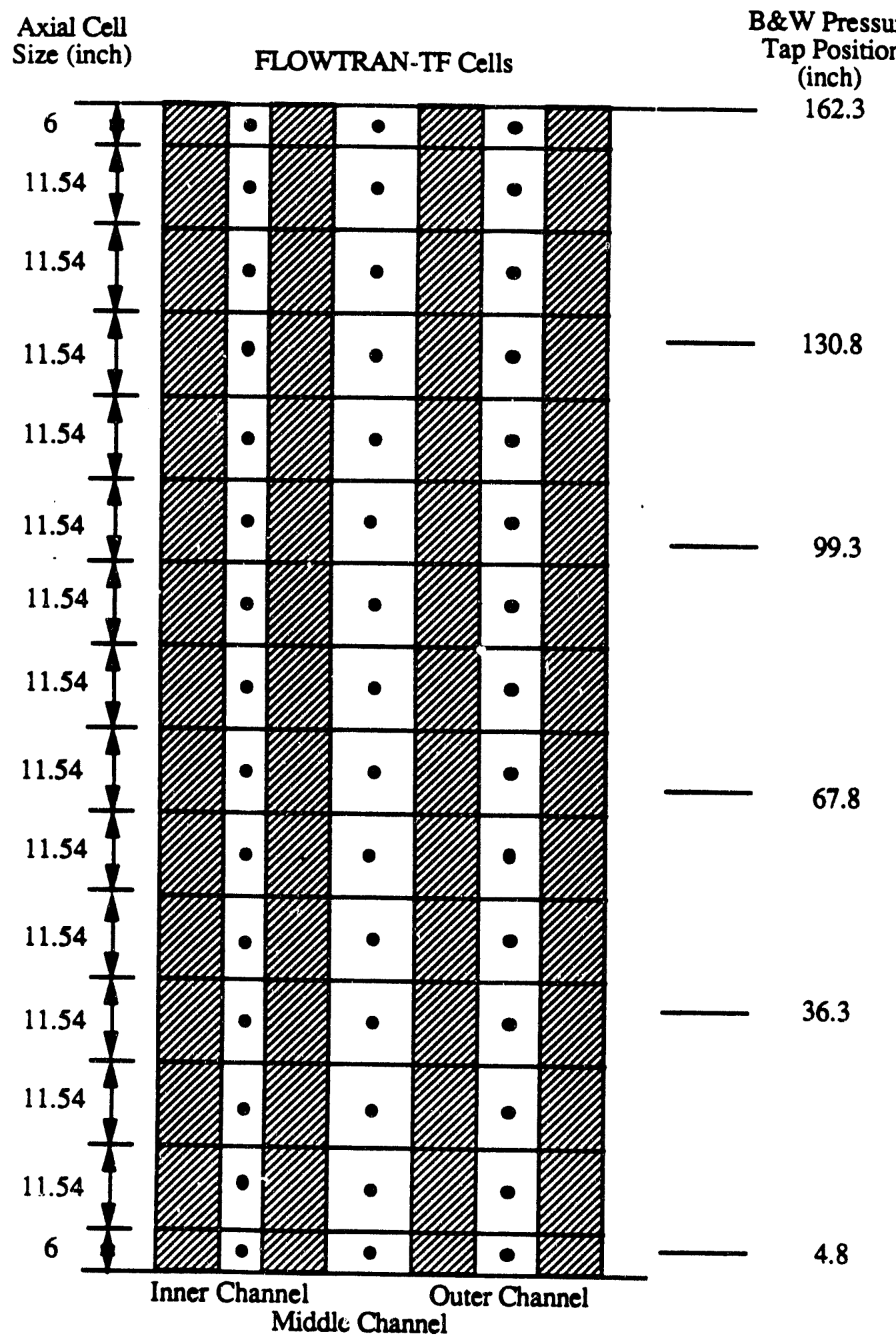

Figure 6.3 Axial nodalization for Middle Section of Mark-22 assembly 


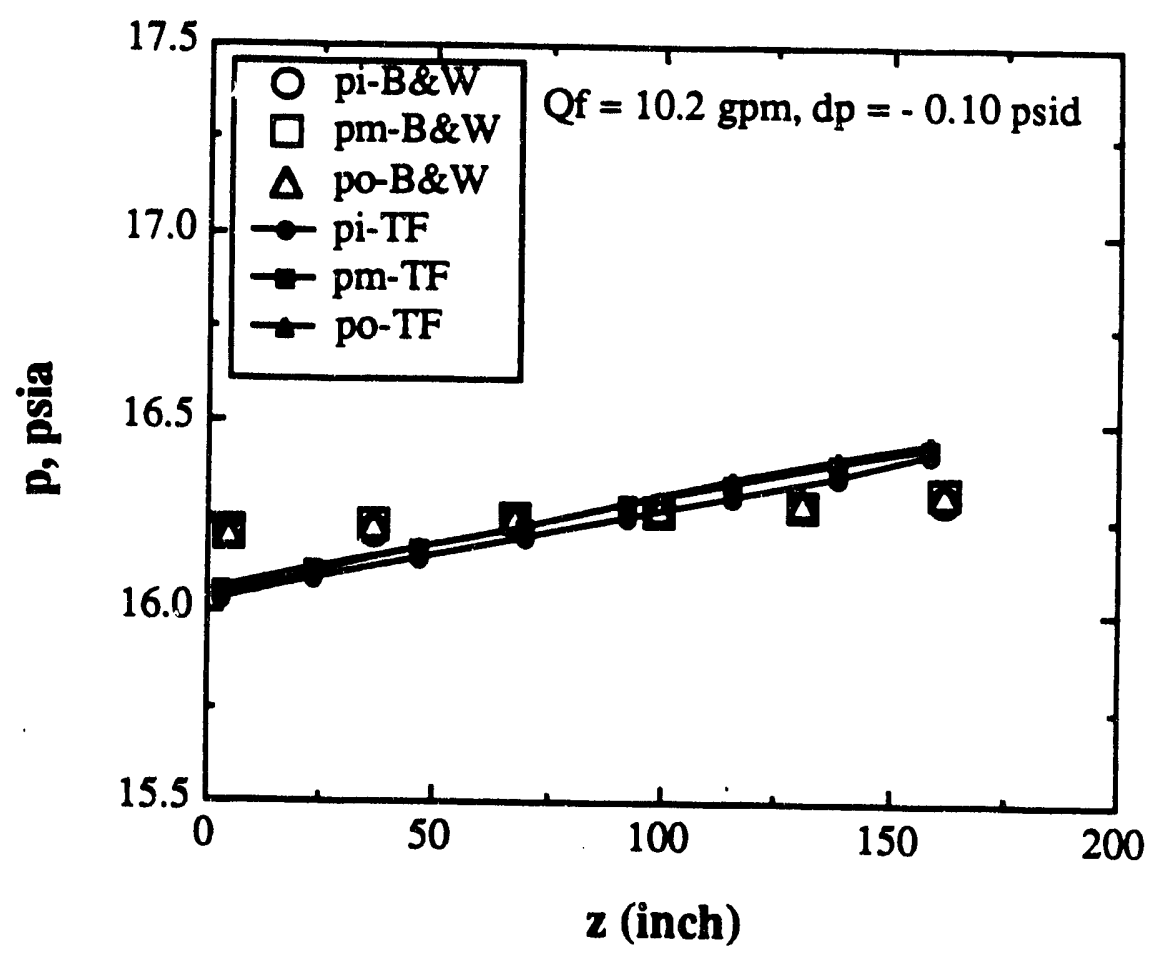

Figure 6.4 Comparison of FLOWTRAN-TF predicted pressure profiles with AFD data for $\mathrm{Qf}=10.2 \mathrm{gpm}$ and dp (assembly pressure drop) $=-0.10 \mathrm{psid}$ 


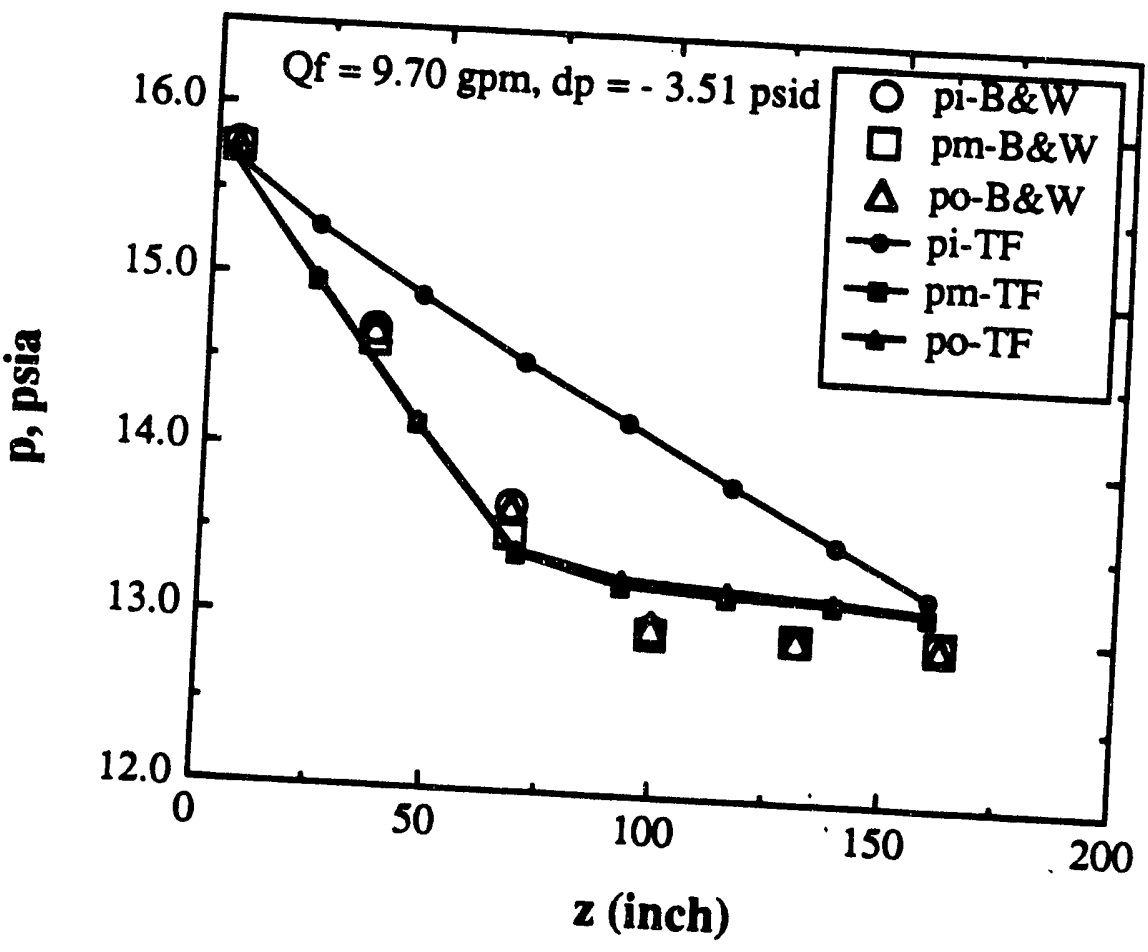
Figure 6.5 Comparison of FLOWTRAN-TF predicted pressure profiles with AFD data
for $\mathrm{Qf}=9.70 \mathrm{gpm}$ and dp (assembly pressure drop) $=-3.51$ psid
16.5

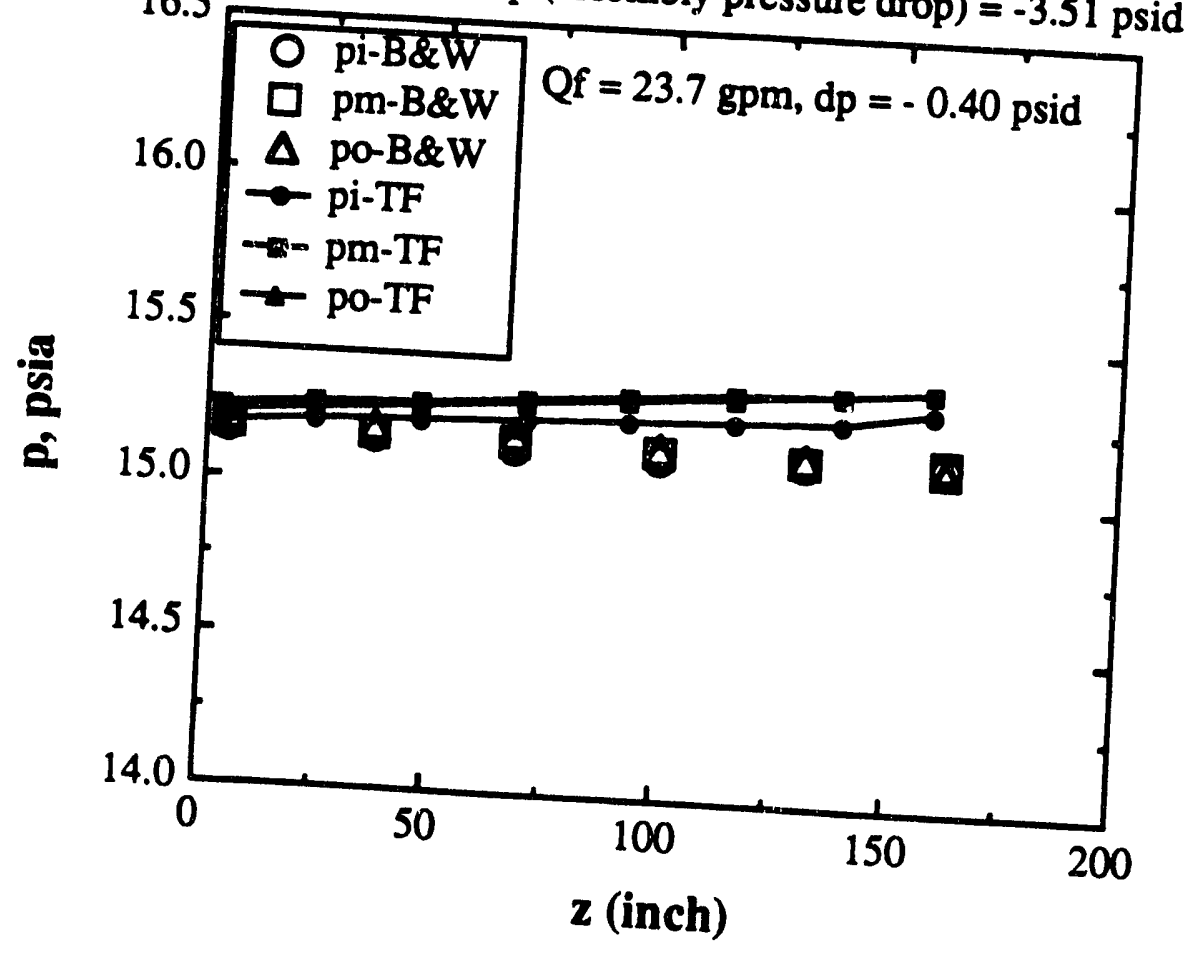

Figure 6.6 Comparison of FLOWTRAN-TF predicted pressure profiles with AFD data
for $Q f=23.7$ gpm and dp (assembly pressure drop) $=-0.40$ psid 


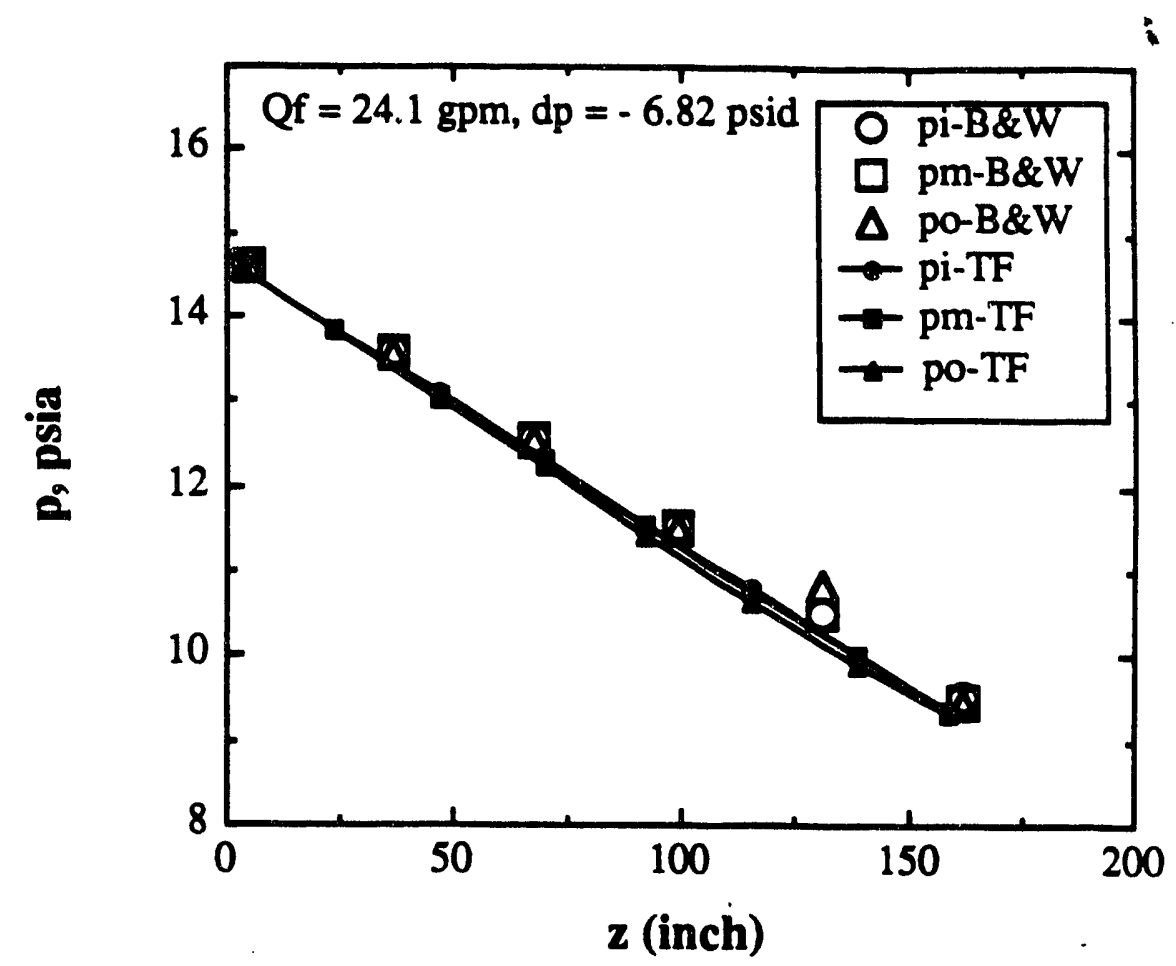

Figure 6.7 Comparison of FLOWTRAN-TF predicted pressure profiles with AFD data for $\mathrm{Qf}=24.1 \mathrm{gpm}$ and dp (assembly pressure drop) $=-6.82 \mathrm{psid}$

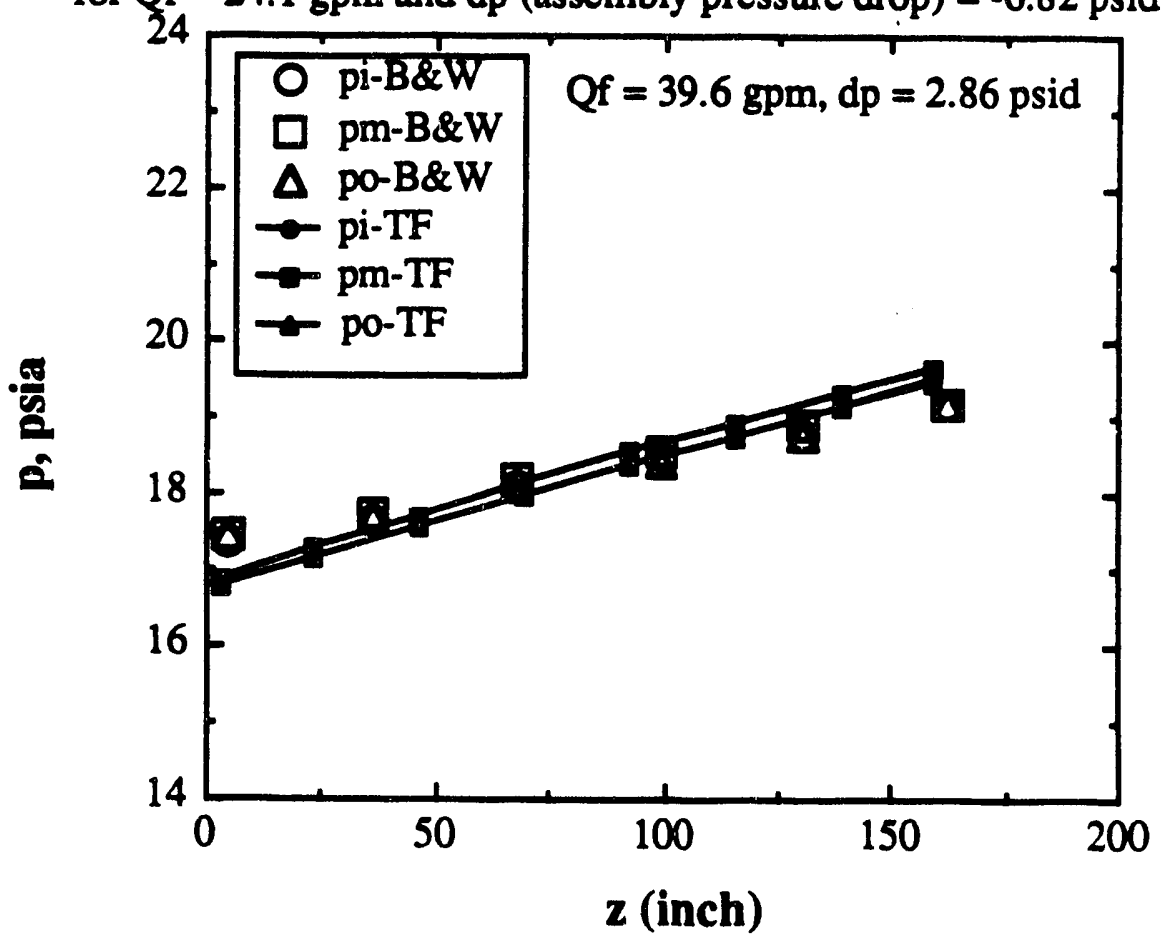

Figure 6.8 Comparison of FLOWTRAN-TF predicted pressure profiles with AFD data for $\mathrm{Qf}=39.6 \mathrm{gpm}$ and dp (assembly pressure drop) $=2.86 \mathrm{psid}$ 


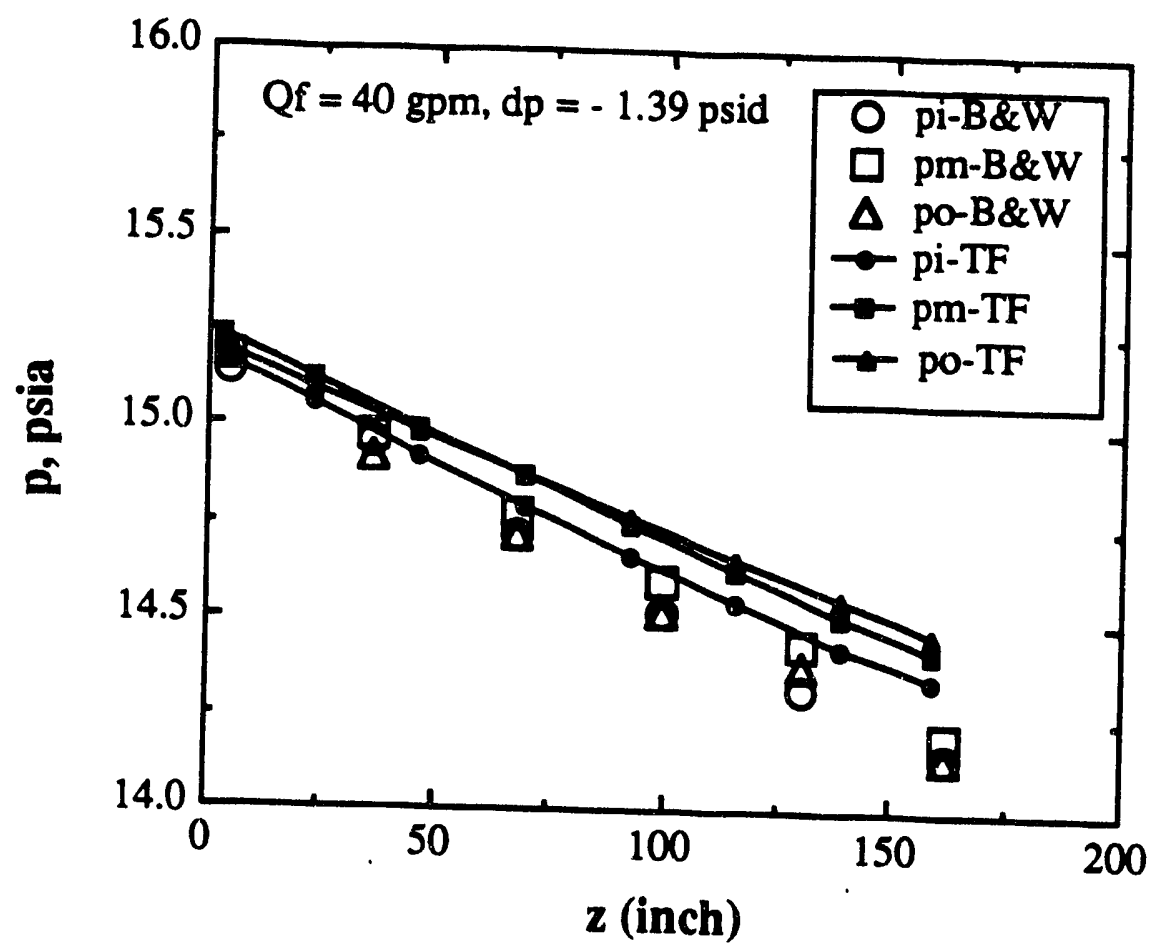

Figure 6.9 Comparison of FLOWTRAN-TF predicted pressure profiles with AFD data for $\mathrm{Qf}=40 \mathrm{gpm}$ and dp (assembly pressure drop) $=-1.39 \mathrm{psid}$

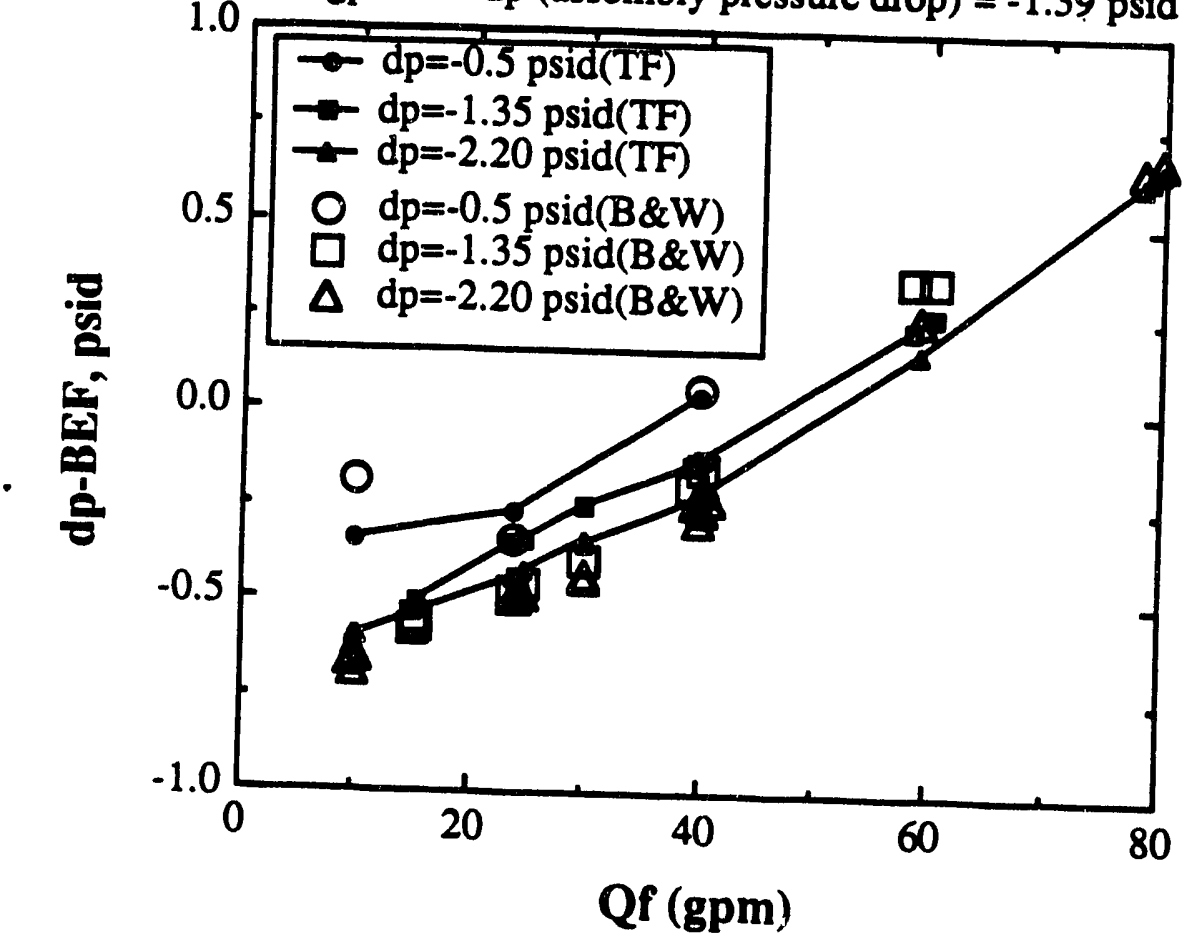

Figure 6.10 Bottom Fitting Insert pressure difference benchmarking results 


\section{Heated, Single Channel Integral Benchmarking Results}

Heated, single-channel experiments currently provide the primary data base for integral benchmarking of the FLOWTRAN-TF code. These integral benchmarks provide verification that the code will predict reasonably accurate best-estima ${ }^{-a}(\mathrm{BE})$ of the power required to reach the current ECS limit criterion of $T_{\text {wall }}=T_{\text {sat }}\left(S_{n}\right.$ th et al., 1990a; $1990 \mathrm{~b}$ ) and to reach the onset of thermal excursion (OTE). The $T_{\text {wall }}=T_{\text {sat }}$ criterion defines the power level at which the maximum time averaged wall surface temperature matches the local fluid saturation temperature. For brevity we refer to this criterion as the ' $T$ wall' criterion. The OTE power level is defined as the power at which metal temperatures exceed $250^{\circ} \mathrm{C}$. The OTE powers represent a physical safety constraint for the experimental rigs while the $T_{\text {wall }}$ powers are a convenient limit which is shown to be a precursor to OTE.

In addition to benchmarking FLOWTRAN-TF used as a best-estimate tool, we also present benchmarking results for the ECS Power Limits Methodology described by Smith et al. (1990a, b). The ECS Limits Methodology is applied to the experimental rigs, as applicable, and conservative $T_{\text {wall }}$ powers are generated. Comparisons to the heated, single-channel data illustrate the margin between the conservative $T_{\text {wall }}$ predictions and the $T_{w a l l}$ data and the (much larger) physical safety margin between the conservative $T_{\text {wall }}$ predictions and the OTE data.

\subsection{Twall = Tsat and Onset of Thermal Excursion Powers}

We expect conservative-estimate $T_{\text {wall }}$ powers to always be well below OTE powers. A gross verification of this expectation is demonstrated in Fig. 7.1, which shows OTE data from four different test rigs within the range of boundary conditions expected to occur in reactor assemblies during a DEGB LOCA and the calculated conservative-estimate (CE) $T_{\text {wall }}$ powers for two of the test rigs (ETH/NES, 1990; NES-CDG-900015, 1990). The comparison is made on a saturation ratio basis. The saturation ratio, $R$, is defined as

$$
R=\frac{P_{\text {criterion }}}{P_{\text {sat }}}=\frac{P_{\text {criterion }}}{\dot{\dot{m}_{\mathbf{p}}\left(T_{\text {sat }}-T_{\text {in }}\right)}}
$$

where

$$
\begin{aligned}
P_{\text {criterion }} & \equiv \text { Power to reach chosen criterion }\left(T_{\text {wall }} \text { or } O T E\right) \\
\dot{\mathrm{m}} & \equiv \text { Liquid mass flowrate through channel } \\
c_{p} & \equiv \text { Liquid specific heat capacity } \\
T_{\text {sat }} & \equiv \text { Channel outlet fluid saturation temperature } \\
T_{\text {in }} & \equiv \text { Channel inlet fluid temperature }
\end{aligned}
$$

The calculated results were obtained using typical boundary conditions of $45^{\circ} \mathrm{C}$ inlet temperature, an atmospheric inlet plenum, and a $3^{\prime}$ outlet tank level. The anticipated ranges of reactor assembly conditions in a DEGB LOCA are: 
- -3.5 to +0.4 psi pressure difference (inlet minus outlet)

- 15 to $50^{\circ} \mathrm{C}$ inlet temperature

- 0.17 to $1.34 \mathrm{~m} / \mathrm{s}$ superficial liquid velocity.

As expected, the calculated CE $T_{\text {wall }}$ curves fall well below any of the OTE data, even though the OTE data include tests with boundary conditions other than those used for the calculations.

Figures 7.2 and 7.3 show benchmark results for a set of experiments conducted on Rig FA (Steimke, 1990a; NES-CDG-900015) at several liquid flow rates with boundary conditions representative of those expected to occur during the DEGB LOCA. Rig FA has an aluminum heating surface with a nearly uniform heat flux. Figure 7.2 presents results in terms of power, while Fig. 7.3 shows the same information in terms of the saturation ratio. The computed OTE powers are consistently lower than the observed OTE powers, whereas the computed best estimate (BE) $T_{\text {well }}$ powers are essentially within the error bars for the experimentally observed values. The conservative estimate $T_{\text {wall }}$ powers are well below the observed $T_{\text {wall }}$ powers in all cases and also demonstrate that a considerable safety margin exists before OTE is reached. The determination of experimental error bars is discussed below.

Figures 7.4 and 7.5 present benchmark comparisons for Rig FB (Johnston, 1990a; NESCDG-900015, 1990) for the same test conditions imposed on Rig FA. Rig FB has an aluminum heating surface with a $\pm 10 \%$ azimuthal power tilt. There is more scatter in the OTE data from Rig FB. The FLOWTRAN-TF predictions lie fairly close to the OTE data, except at higher flows where the code underpredicts. The agreement between the calculated and observed $T_{\text {wall }}$ powers is not quite as good as that for Rig FA, but the computed CE powers are still well below the experimental $\mathrm{T}_{\text {wall }}$ and $O \mathrm{TE}$ observations.

Tables 7.1 and 7.2 summarize the benchmarking results illustrated in Figs. 7.2 and 7.4 for Rigs FA and FB, respectively. In addition, these tables also break out the impacts on the $C E T_{\text {wall }}$ power of the most significant sensitivity variables. The sensitivity variable impacts are responsible for the spread between the $B E$ and $C E T_{\text {wall }}$ powers. Heat transfer coefficient uncertainty dominates the analyses for both rigs. Some sensitivity variable settings did not result in a power lower than the nominal value. This behavior is indicated in Tables 7.1 and 7.2 with a > symbol. Eccentricity is already bounded in the nominal run for Rig FB and therefore does not appear in the sensitivity variable list. The conservative power estimate is constructed by subtracting from the nominal power the root-sum-square of the deviations from nominal.

Figure 7.6 and Table 7.3 present experimental and computational results that show the impact of assembly pressure drops on computed $T_{\text {wall }}$ power levels. For OTE, both the experimental data and the code predictions show increasing power with increasing pressure difference (defined to be inlet minus outlet pressure). The experimental powers for the $T_{\text {wall }}$ criterion display a minimum at zero pressure drop which is not duplicated by the $B E$ calculations; however, the correct trend is observed in the CE predictions. The uncertainty terms (Table 7.3) again drop the CE $T_{\text {wall }}$ powers well below the observed powers.

The various single channel heated rigs are normally operated under steady pressure and liquid flow boundary conditions (NES-CDG-900015, 1990). Oscillatory boundary conditions are expected in the DEGB LOCA based on L-Area data (Van Brunt, 1990). Therefore, a series of Rig FA experiments was conducted to examine the effect of flow 
oscillations on both OTE and $T_{\text {wall }}$ powers. Based on an examination of 1989 L-Area data and RELAP5 results, worst-case flow oscillations with a $\pm 30 \%$ amplitude and 6.5 second period were selected for the experimental studies. As illustrated in Fig. 7.7, the impact on power due to oscillatory inlet liquid flow appears to be insignificant except possibly at 12 gpm for the OTE power. FLOWTRAN-TF best-estimate predictions of $T_{\text {wall }}$ power at 9 gpm for sscillating inlet flow (not shown) also indicate no impact on the power limit in agreement with the experimental data.

Each experimental error bar shown in Figs. 7.1-7 is a $\pm 5 \%$ band which is an average uncertainty value as discussed below (ETH/NES, 1990; NES-CDG-900015, 1990). The uncertainty in specifying the power at the $\mathrm{T}_{\text {wall }}=\mathrm{T}_{\text {sat }}$ criterion is estimated by a root-sumsquare combination of two quantities:

1. Uncertainty in power

2. Uncertainty in the inner wall temperature.

The temperature uncertainty is in turn a root-sum-square combination of three quantities:

1. Uncertainty in determining the outer wall temperature

2. Uncertainty in heat conduction calculation for the inner wall temperature

3. Inherent variability of the inner wall temperature with the uncontrolled local flow distribution.

The temperature measurement uncertainty is taken as $\pm 1^{\circ} \mathrm{C}$. The uncertainty in the heat conduction calculation is indicated by the variability of the overall tube wall conductance determined by single phase heat transfer measurements. This was found to be numerically equal to $0.8 \%$ of the power, expressed in $\mathrm{kW}$. The inherent inner wall temperature variability is estimated by taking twice the standard error of estimate for the linear fit between inner wall temperature and measured power in each individual experiment. These three contributions to the inner wall temperature uncertainty are combined using the rootsum-square technique. The resulting uncertainty is then divided by the slope of the linear fit between inner wall temperature and power to convert it to a power basis. Combining this with the power uncertainty, which is taken to be $\pm 3.8 \%$, results in an overall uncertainty of about $\pm 5 \%$. Results for individual flowrates are shown in Table 7.4. Because each of the component uncertainties are specified to include about $90 \%$ of the data, this result may be regarded as a "2-sigma" estimate of uncertainty in the $T_{\text {sat }}$ criterion power. 


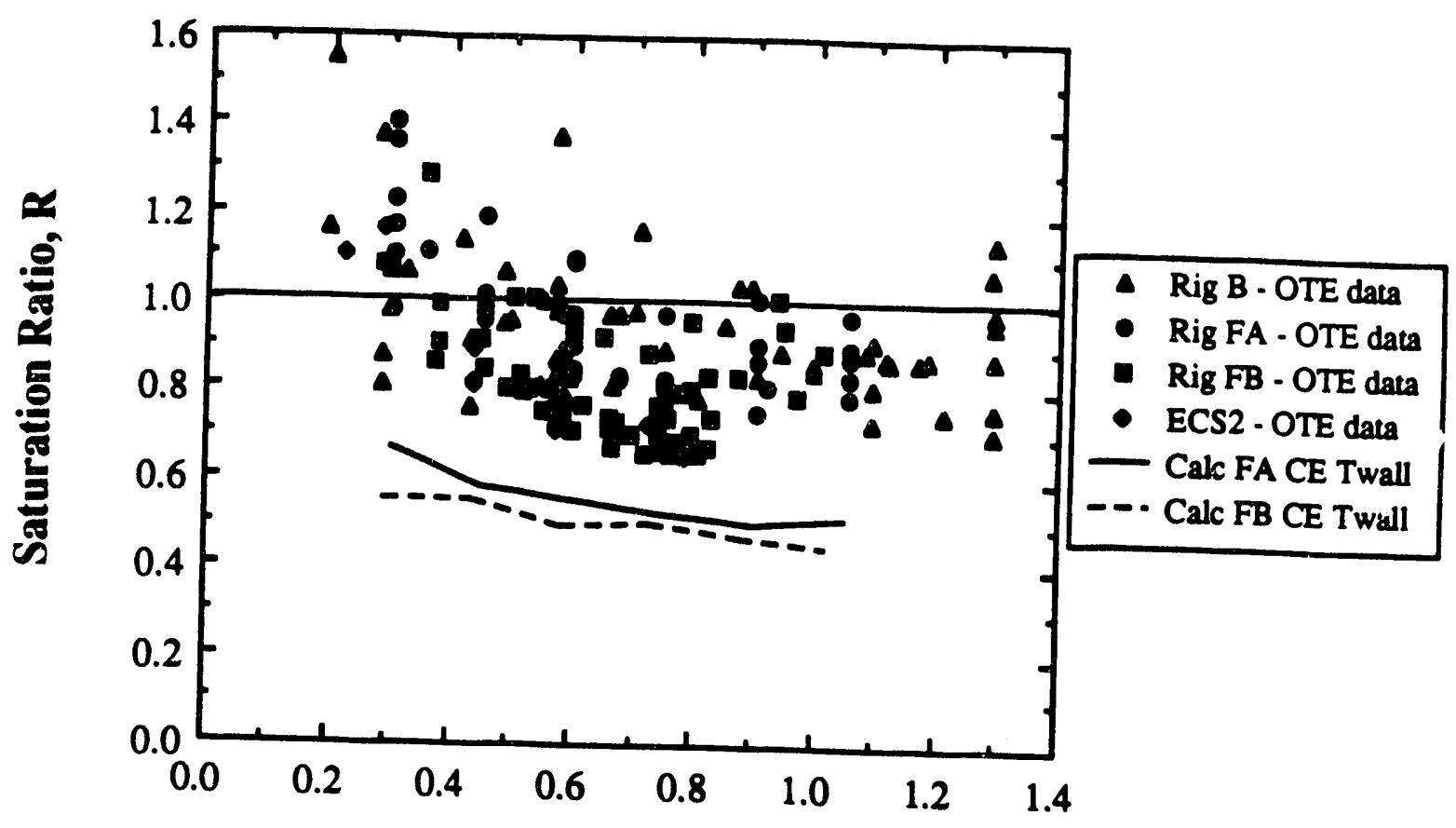

\section{Liquid Superficial Velocity, $\mathrm{m} / \mathrm{s}$}

Figure 7.1 Comparison of all OTE data within expected range of DEGB LOCA conditions to typical FLOWTRAN-TF conservative estimate $T_{\text {wall }}$ power
levels for Rigs FA and FB 


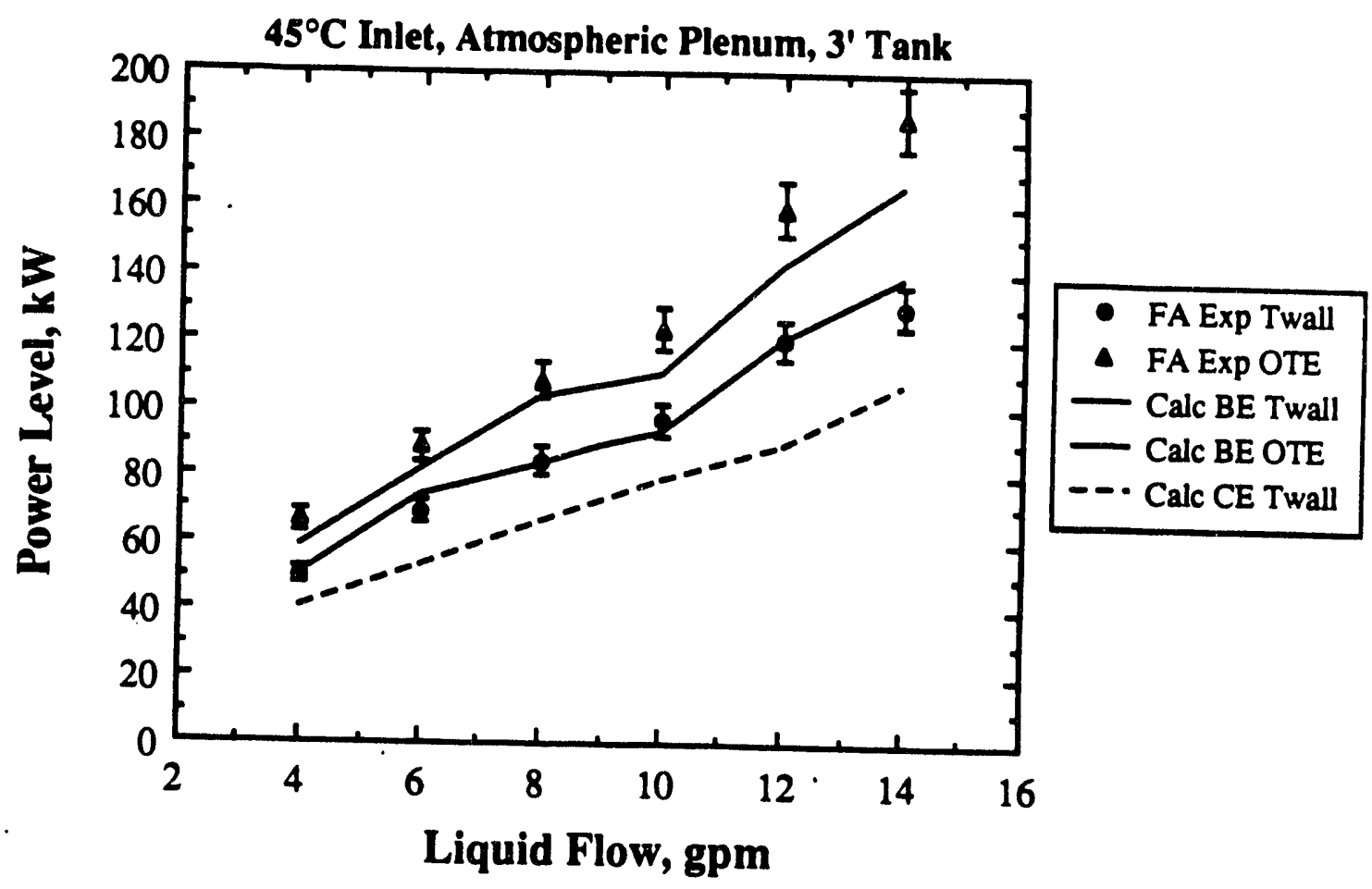

Figure 7.2 Rig FA power level comparison

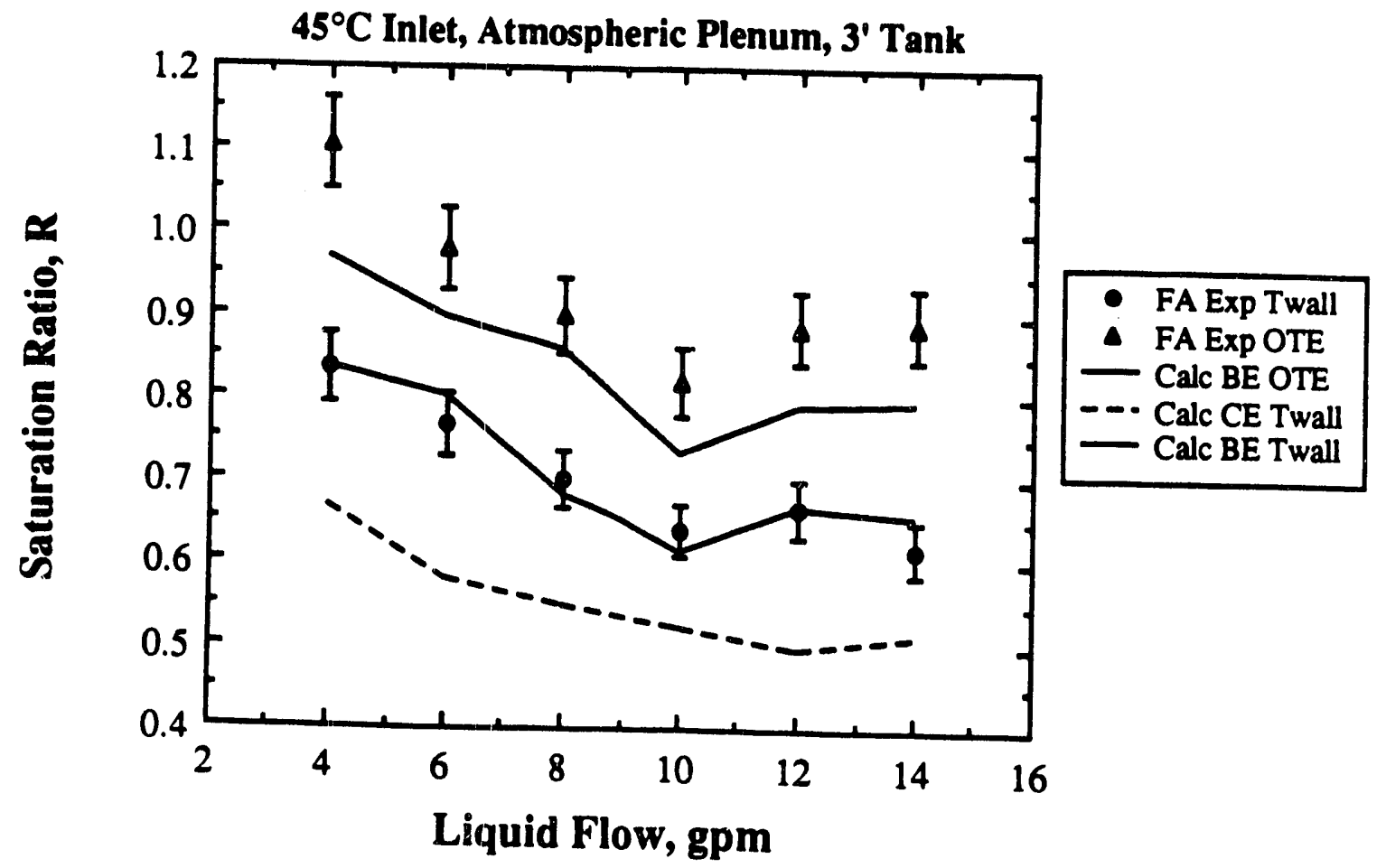

Figure 7.3 Rig FA saturation ratio comparison 


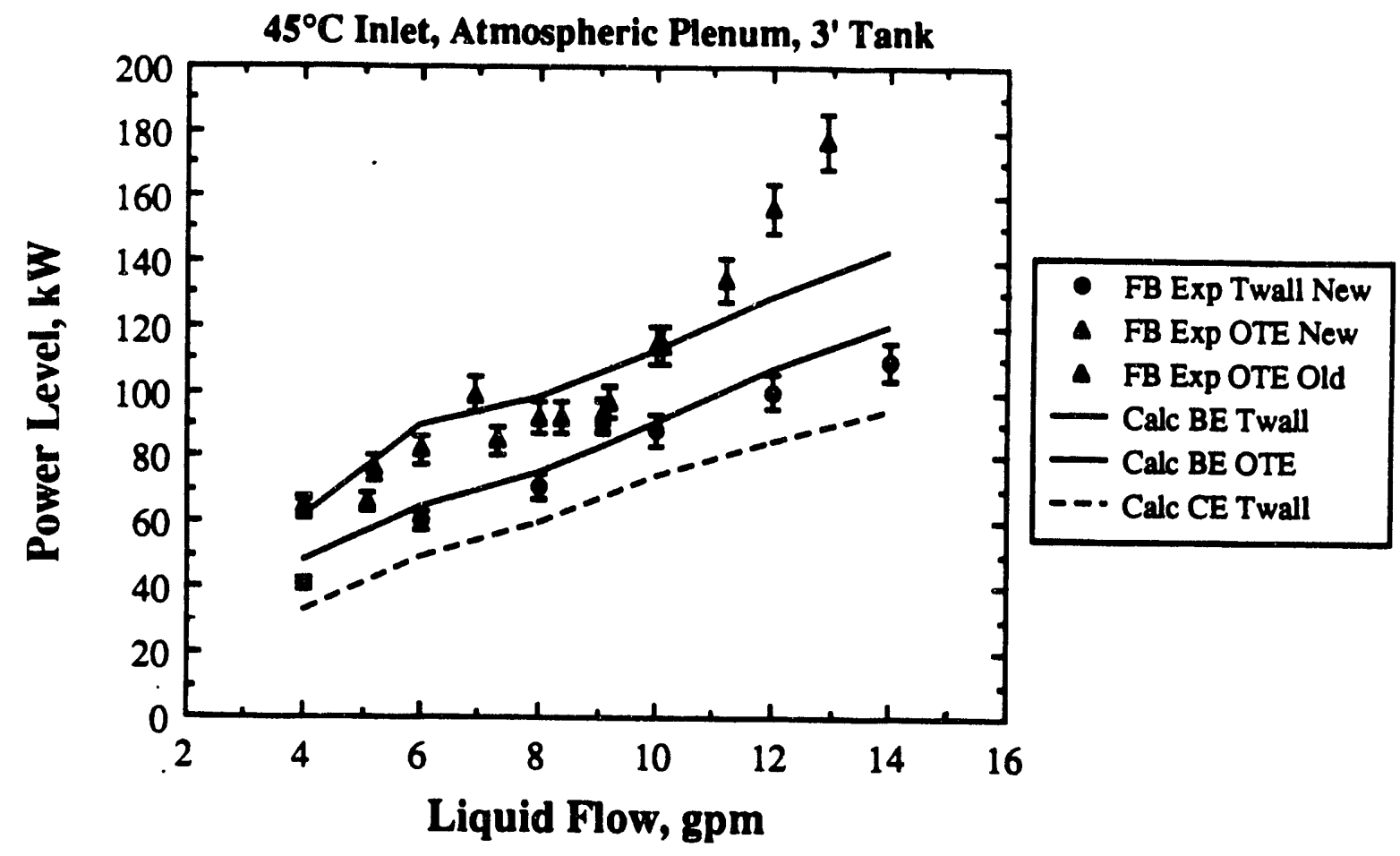

Figure 7.4 Rig FB power level comparison

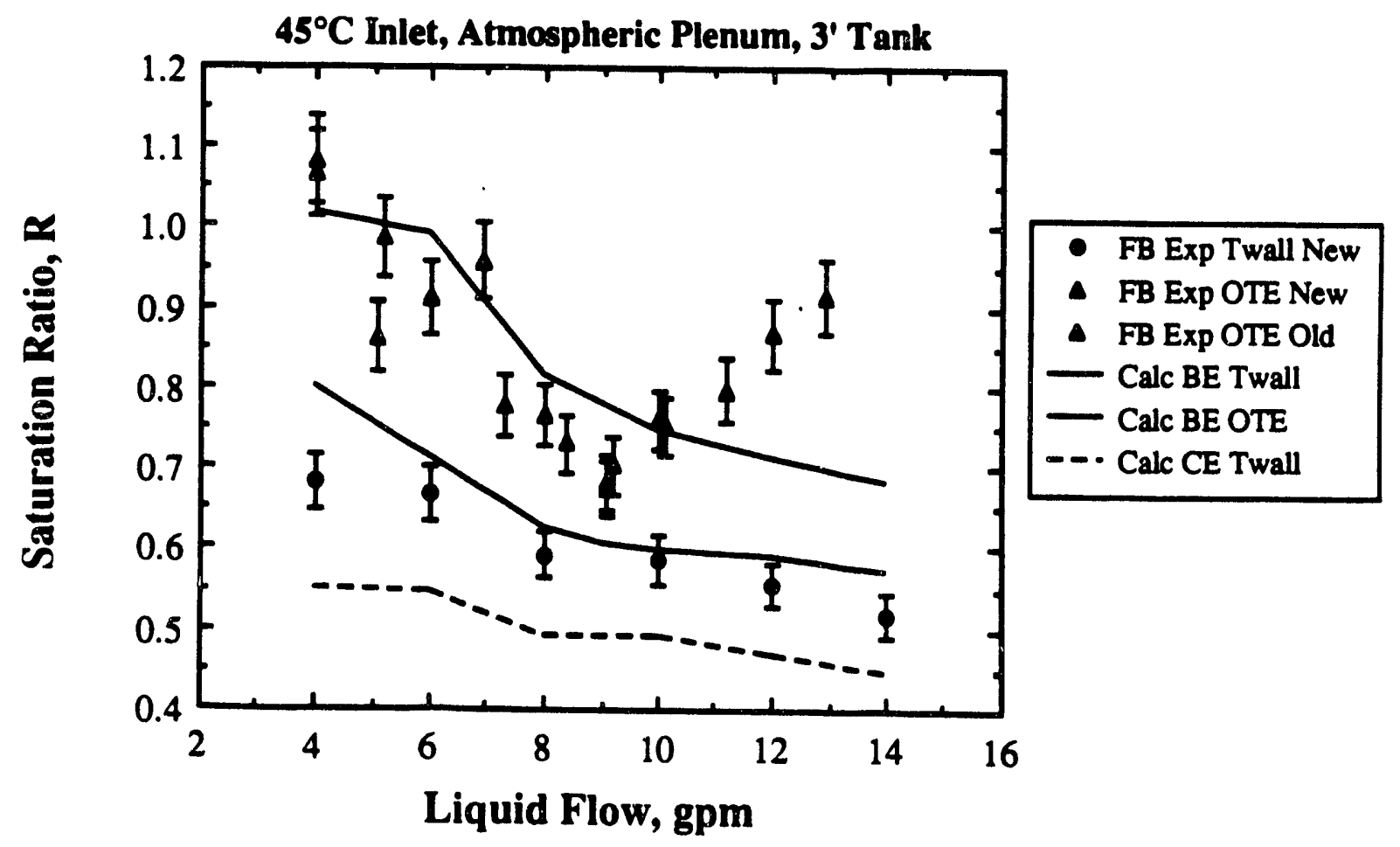

Figure 7.5 Rig FB saturation ratio comparison 


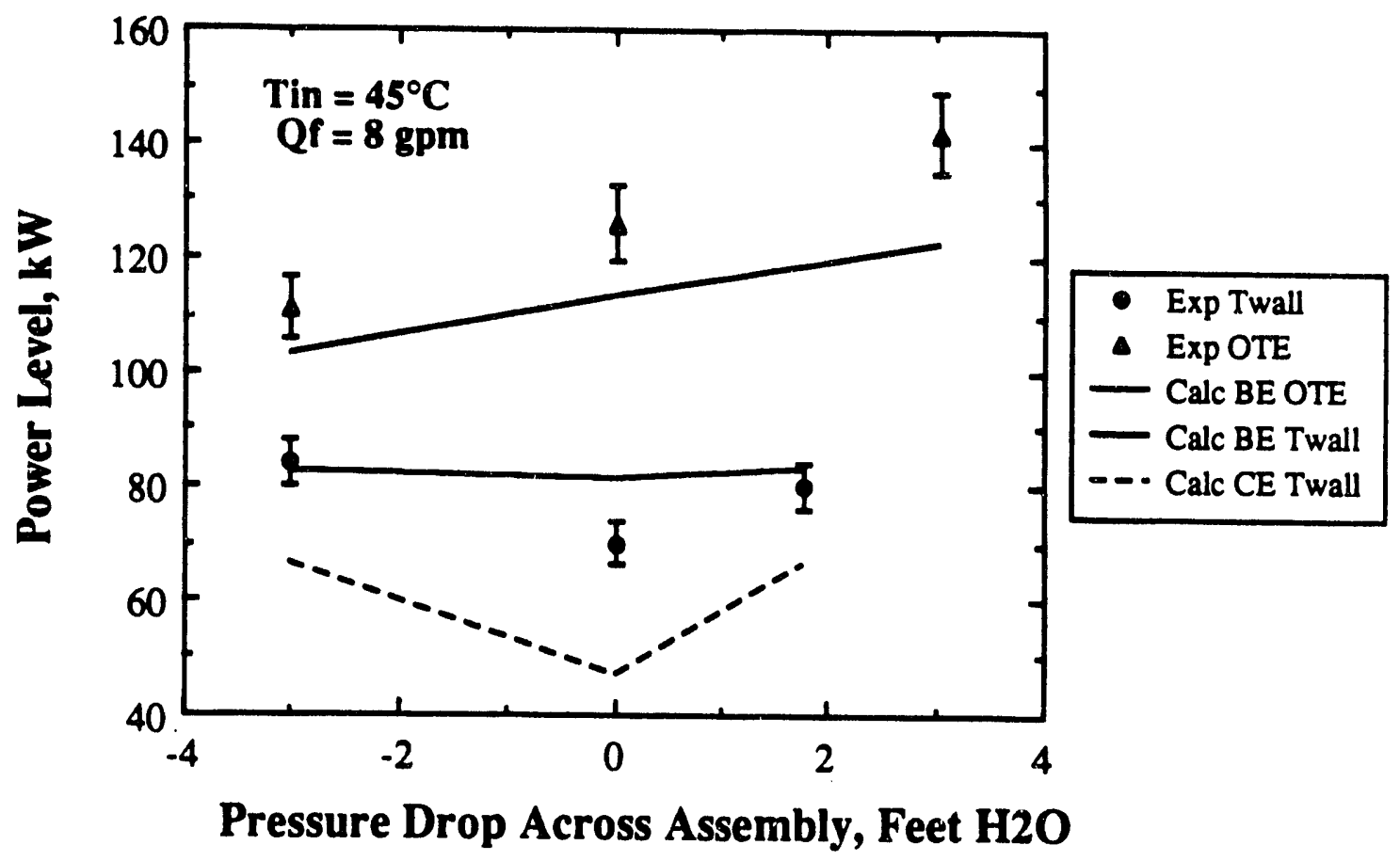

Figure 7.6 Rig FA OTE and $T_{\text {wall }}$ criteria pressure drop sensitivity study

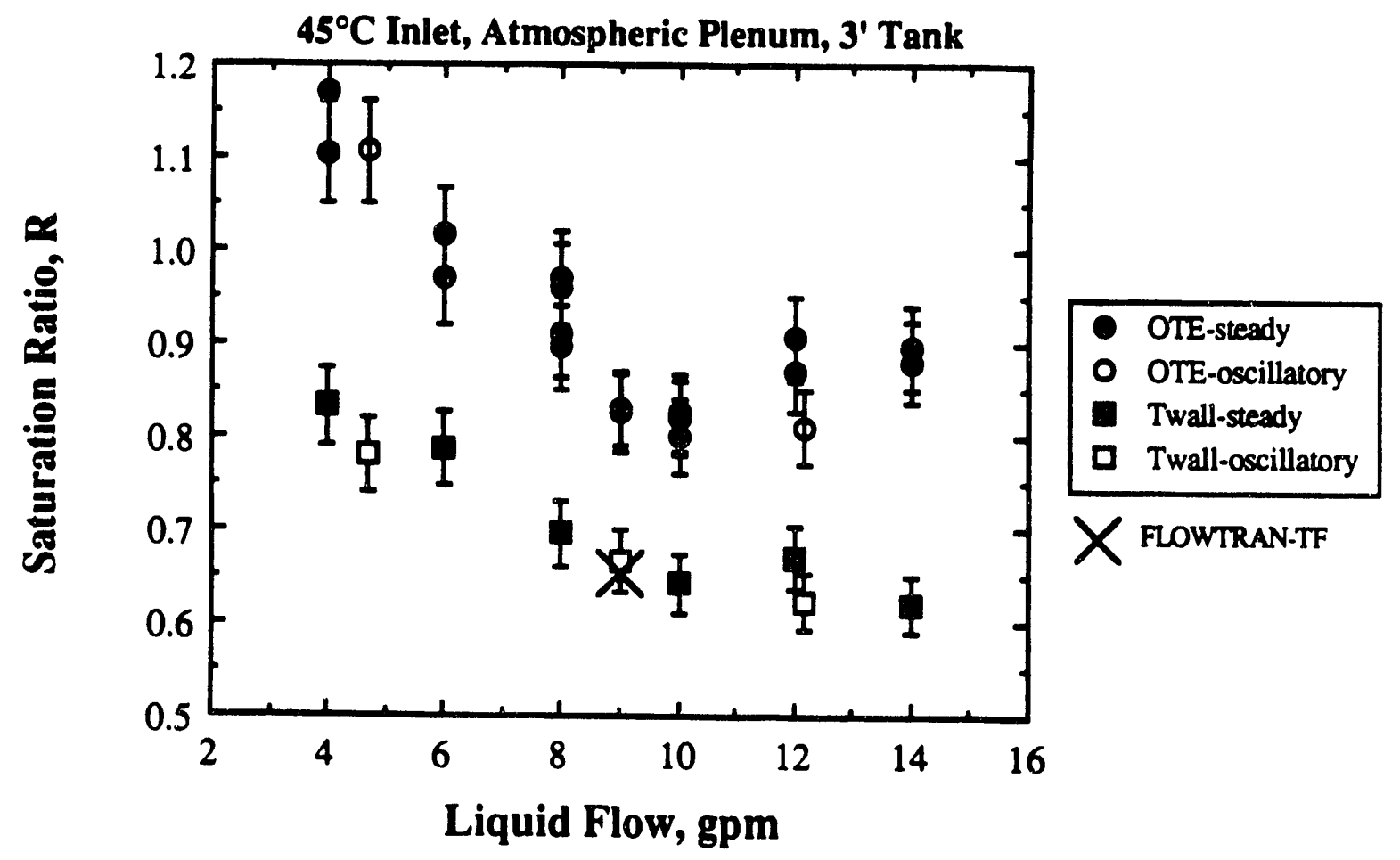

Figure 7.7 Rig FA OTE and $\mathrm{T}_{\text {wall }}$ criteria flow oscillation study 
Table 7.1 FLOWTRAN-TF benchmarking and sensitivity variable runs for Rig FA simulation

\begin{tabular}{|c|c|c|c|c|c|c|c|}
\hline & Liquid Flow: & $\begin{array}{c}4 \\
\text { gpm }\end{array}$ & $\begin{array}{c}6 \\
\text { gpm } \\
\end{array}$ & $\begin{array}{c}8 \\
\text { gpm }\end{array}$ & $\begin{array}{c}10 \\
\text { gpm }\end{array}$ & $\begin{array}{c}12 \\
\mathrm{gpm}\end{array}$ & $\begin{array}{c}14 \\
\text { gpm }\end{array}$ \\
\hline OTE & $\begin{array}{l}\text { Experiment } \\
\text { Best estimate }\end{array}$ & $\begin{array}{c}66 \mathrm{~kW} \\
58 \\
\end{array}$ & $\begin{array}{c}88 \mathrm{~kW} \\
81 \\
\end{array}$ & $\begin{array}{c}108 \mathrm{~kW} \\
103 \\
\end{array}$ & $\begin{array}{c}123 \mathrm{~kW} \\
110 \\
\end{array}$ & $\begin{array}{c}159 \mathrm{~kW} \\
142 \\
\end{array}$ & $\begin{array}{c}187 \mathrm{~kW} \\
166 \\
\end{array}$ \\
\hline Twall & $\begin{array}{l}\text { Experiment } \\
\text { Best estimate } \\
\end{array}$ & $\begin{array}{l}50 \\
50 \\
\end{array}$ & $\begin{array}{l}69 \\
72 \\
\end{array}$ & $\begin{array}{l}84 \\
82 \\
\end{array}$ & $\begin{array}{l}96 \\
92 \\
\end{array}$ & $\begin{array}{l}120 \\
120 \\
\end{array}$ & $\begin{array}{l}130 \\
138 \\
\end{array}$ \\
\hline \multirow{6}{*}{$\begin{array}{c}\text { Sensitivity } \\
\text { variable } \\
\text { list }\end{array}$} & Nominal & 45 & 66 & 76 & 85 & 110 & 125 \\
\hline & Heat trans. & 41 & 60 & 69 & 78 & 97 & 109 \\
\hline & Wall friction & 44 & 62 & 70 & $>85$ & 108 & 123 \\
\hline & Inter. drag & 44 & 58 & 74 & $>85$ & 106 & 124 \\
\hline & Rib void & 43 & 61 & $>76$ & $>85$ & 96 & 125 \\
\hline & Eccentricity & 44 & 59 & 72 & $>85$ & 103 & 116 \\
\hline \multicolumn{2}{|c|}{ Conservative Estimate: } & $40 \mathrm{~kW}$ & $52 \mathrm{~kW}$ & $66 \mathrm{~kW}$ & $78 \mathrm{~kW}$ & $89 \mathrm{~kW}$ & $107 \mathrm{~kW}$ \\
\hline
\end{tabular}

Table 7.2 FLOWTRAN-TF benchmarking and sensitivity variable runs for Rig FB simulation

\begin{tabular}{|c|c|c|c|c|c|c|c|}
\hline & Liquid Flow: & $\begin{array}{c}4 \\
\mathrm{gpm}\end{array}$ & $\begin{array}{c}6 \\
\mathrm{gpm} \\
\end{array}$ & $\begin{array}{c}8 \\
\mathrm{gpm} \\
\end{array}$ & $\begin{array}{r}10 \\
\text { gpm }\end{array}$ & $\begin{array}{r}12 \\
\text { gpm }\end{array}$ & $\begin{array}{r}14 \\
\mathrm{gpm} \\
\end{array}$ \\
\hline OTE & $\begin{array}{l}\text { Experiment } \\
\text { Best estimate }\end{array}$ & $\begin{array}{c}64 \mathrm{~kW} \\
61 \\
\end{array}$ & $\begin{array}{c}82 \mathrm{~kW} \\
89 \\
\end{array}$ & $\begin{array}{c}92 \mathrm{~kW} \\
98 \\
\end{array}$ & $\begin{array}{c}114 \mathrm{~kW} \\
112 \\
\end{array}$ & $\begin{array}{c}156 \mathrm{~kW} \\
128 \\
\end{array}$ & $\begin{array}{c}- \\
143 \\
\end{array}$ \\
\hline Twall & $\begin{array}{l}\text { Experiment } \\
\text { Best estimate }\end{array}$ & $\begin{array}{l}41 \\
48 \\
\end{array}$ & $\begin{array}{l}60 \\
64 \\
\end{array}$ & $\begin{array}{l}71 \\
75 \\
\end{array}$ & $\begin{array}{l}88 \\
90 \\
\end{array}$ & $\begin{array}{l}100 \\
106 \\
\end{array}$ & $\begin{array}{l}109 \\
120 \\
\end{array}$ \\
\hline Sensitivity & Nominal & & 56 & 68 & 82 & 96 & 109 \\
\hline variable & Heat trans. & 38 & 51 & 61 & 74 & 84 & 94 \\
\hline \multirow[t]{3}{*}{ list } & Wall friction & 36 & 56 & 63 & 81 & 94 & 107 \\
\hline & Inter. drag & 36 & 51 & $>68$ & $>82$ & 96 & 109 \\
\hline & Rib void & 42 & $>56$ & 67 & $>82$ & 95 & 109 \\
\hline \multicolumn{2}{|c|}{ Conservative Estimate: } & $33 \mathrm{~kW}$ & $49 \mathrm{~kW}$ & $59 \mathrm{~kW}$ & $74 \mathrm{~kW}$ & $84 \mathrm{~kW}$ & $94 \mathrm{~kW}$ \\
\hline
\end{tabular}


Table 7.3 FLOWTRAN-TF benchmarking and sensitivity variable runs for Rig FA simulation - pressure drop sensitivity study

\begin{tabular}{|c|c|c|c|c|c|}
\hline \multicolumn{2}{|c|}{ Pressure Difference: } & $-3 \mathrm{ft}$ & $0 \mathrm{ft}$ & $1.78 \mathrm{ft}$ & $3.05 \mathrm{ft}$ \\
\hline \multirow[t]{2}{*}{ OTE } & Experiment & $108 \mathrm{~kW}$ & $126 \mathrm{~kW}$ & - & $142 \mathrm{~kW}$ \\
\hline & Best estimate & 103 & 113 & - & 122 \\
\hline \multirow[t]{2}{*}{ Twall } & Experiment & 84 & 70 & 80 & - \\
\hline & Best estimate & 82 & 81 & 83 & - \\
\hline \multirow{6}{*}{$\begin{array}{c}\text { Sensitivity } \\
\text { variable } \\
\text { list }\end{array}$} & Nominal & 76 & 75 & 79 & - \\
\hline & Heat transfer coef. & 69 & 70 & 73 & - \\
\hline & Wall friction & 70 & 74 & 78 & - \\
\hline & Interfacial drag & 74 & $>75$ & $>79$ & - \\
\hline & Rib void & $>76$ & 47 & 68 & - \\
\hline & Eccentricity & 72 & 74 & 75 & - \\
\hline \multicolumn{2}{|c|}{ Conservative Estimate: } & $66 \mathrm{~kW}$ & $47 \mathrm{~kW}$ & $66 \mathrm{~kW}$ & - \\
\hline
\end{tabular}

Table 7.4 Rig FB Twall power limit uncertainty

\begin{tabular}{|c|c|c|}
\hline Flow (gpm) & Power (kW) & Uncertainty (\%) \\
\hline 4 & 41.2 & \pm 6.2 \\
\hline 6 & 59.9 & \pm 4.9 \\
\hline 8 & 71.4 & \pm 4.5 \\
\hline 10 & 88.5 & \pm 4.6 \\
\hline 12 & 99.7 & \pm 4.2 \\
\hline 14 & 109.2 & \pm 4.6 \\
\hline
\end{tabular}

\subsection{Detailed Temperature Benchmarking Results}

In addition to the integral benchmarking described above, we can also compare FLOWTRAN-TF predictions of temperature profiles to the experimental data to further validate the code calculations. Representative comparisons of fluid temperatures and metal temperatures on the outer wall of the heater for Rig FA (Steimke, 1990) are presented in Figs. 7.8 and 7.9 and similar results for Rig FB (Johnston, 1990) are shown in Figs. 7.10 and 7.11. Both rigs are single channels with the heater on the outer surface. The composite heaters have an inner aluminum surface to simulate conditions in a reactor assembly. For the comparisons we have chosen flowrates of $8 \mathrm{gpm}$ and $10 \mathrm{gpm}$, near the middle of the range of interest, to provide typical benchmarks. The experimental data represent five minute time averages taken at steady operating conditions. 
Rig FA has about a $\pm 2 \%$ azimuthal power variation with the distribution peaking in sibchannel $A$ and at a minimum in subchannel $C$. The experimental data presented in Fig. the fluid in subchannel $C$, the fluid in subchannel $A$ is somewhat hotter than average and and lie between the temperature extremes. reproduced quite well by FLrature extremes. The observed experimental behavior is along the length of The experimentally measured temperature we have assumed a uniform axial power shape. near the entrance to the heated channel. This may be caused $D$ are hotter than expected experimental rig which is not modeled in the code.

The $T_{\text {ivall }}=T_{\text {sat }}$ power limit criterion involves the temperature of the metal surface in contact with the flow. In the Rig FA and FB experiments, the temperature on the outer surface of the heater was measured and the inner wall temperature (contacting the flow) was inferred. In Fig. 7.9, we show FLOWTRAN-TF predictions of the outer wall temperatures in order to compare to directly measured values. In general, the metal FLOWTRAN-TF is able to the same pattern seen in the fluid temperatures. $C$, and D with good accuracy. expected near the channel inlet and then become fubchannel $A$ are significantly hotter than channel. FLOWTRAN-TF predicts a lineare colder than expected near the middle of the subchannel and tends to overpredict the temperaure in in the metal temperatures for each in the hot subchannel near the exit.

Rig FB has a $9.5 \%$ azimuthal power tilt centered about the rib separating subchannels $A$ and $D$. As stown in Fig. 7.10, the experimental fluid temperatures in subchannels $A$ and $D$ are generally higher. FLOWTRAN-TF predicts a wider range in fluid temperatures than is observed experimentally. This may result from the severe eccentricity and bowing assumed in the model calculation. Because of the large azimuthal power tilt, we assume that the channel is fully eccentric in the direction of the tilt and we assume a fixed bowing $A$ and $D$ and induce fli direction. This geometry will reduce the flow areas to subchannels half of the rig. In reality, vibration in the sunnels into the $B$ and $C$ subchannels in the upper bowing prodicill tend to average out the eccentricity and FLOWTRAN-TF

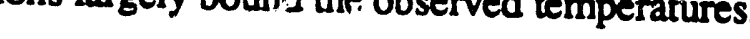

Metal temperatures for Rig FB are shown in Fig. 7.11. The outer metal surfaces for subchannels $A$ and $D$ are generally higher than those for subchannels B and C. As with the observed experimentally. temperatures in subchannel Azimuthal cross-flow in the model also separates the FLOWTRAN-TF calculations $A$ and $D$ more than is actually measured. Again, the this power level, the outer surface approaches outlet to the channel. The inner approaches $100^{\circ} \mathrm{C}$ as a maximum temperature at the experimental conditions. 


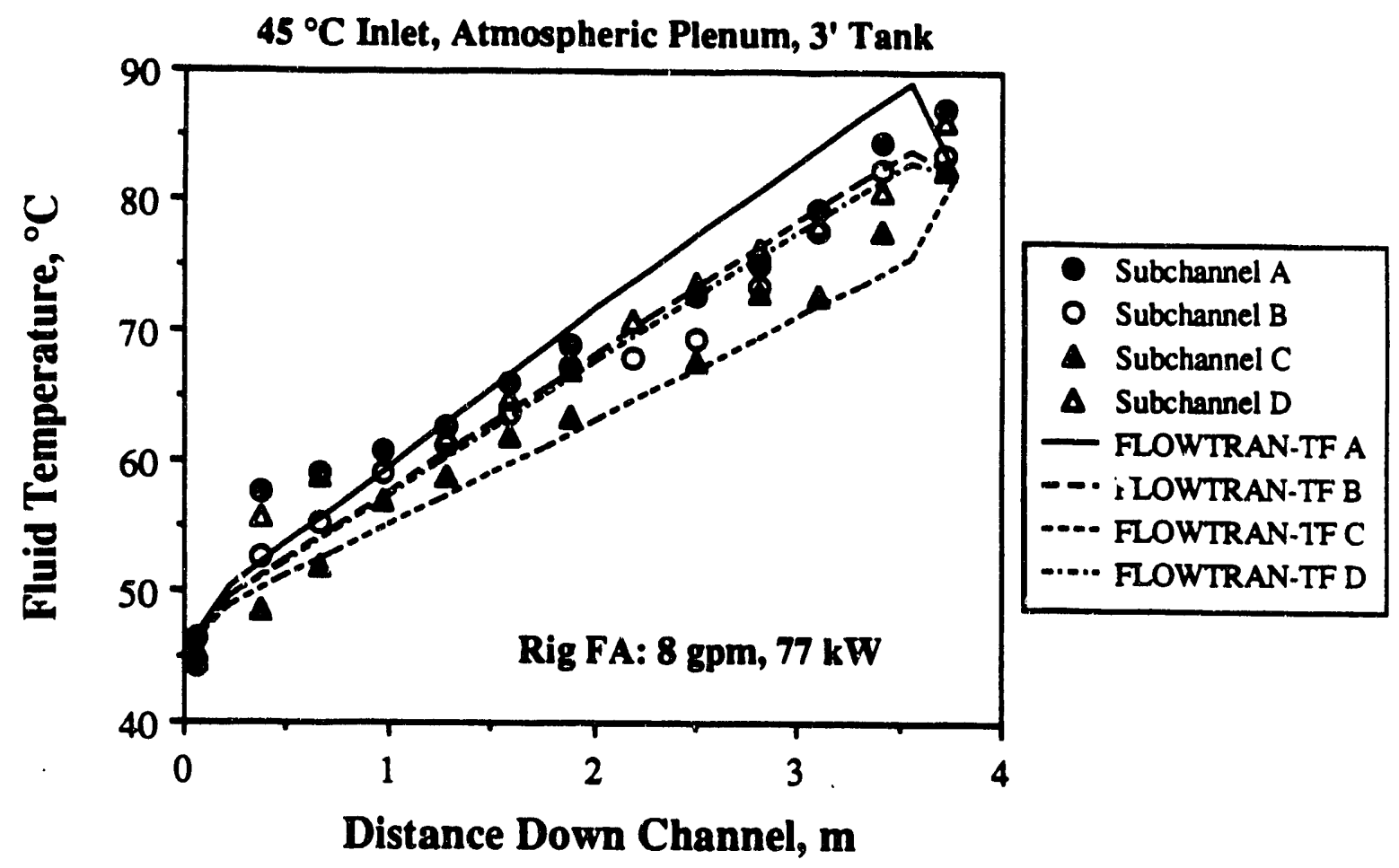

Figure 7.8 Fluid temperatures in Rig FA compared to FLOWTRAN-TF predictions

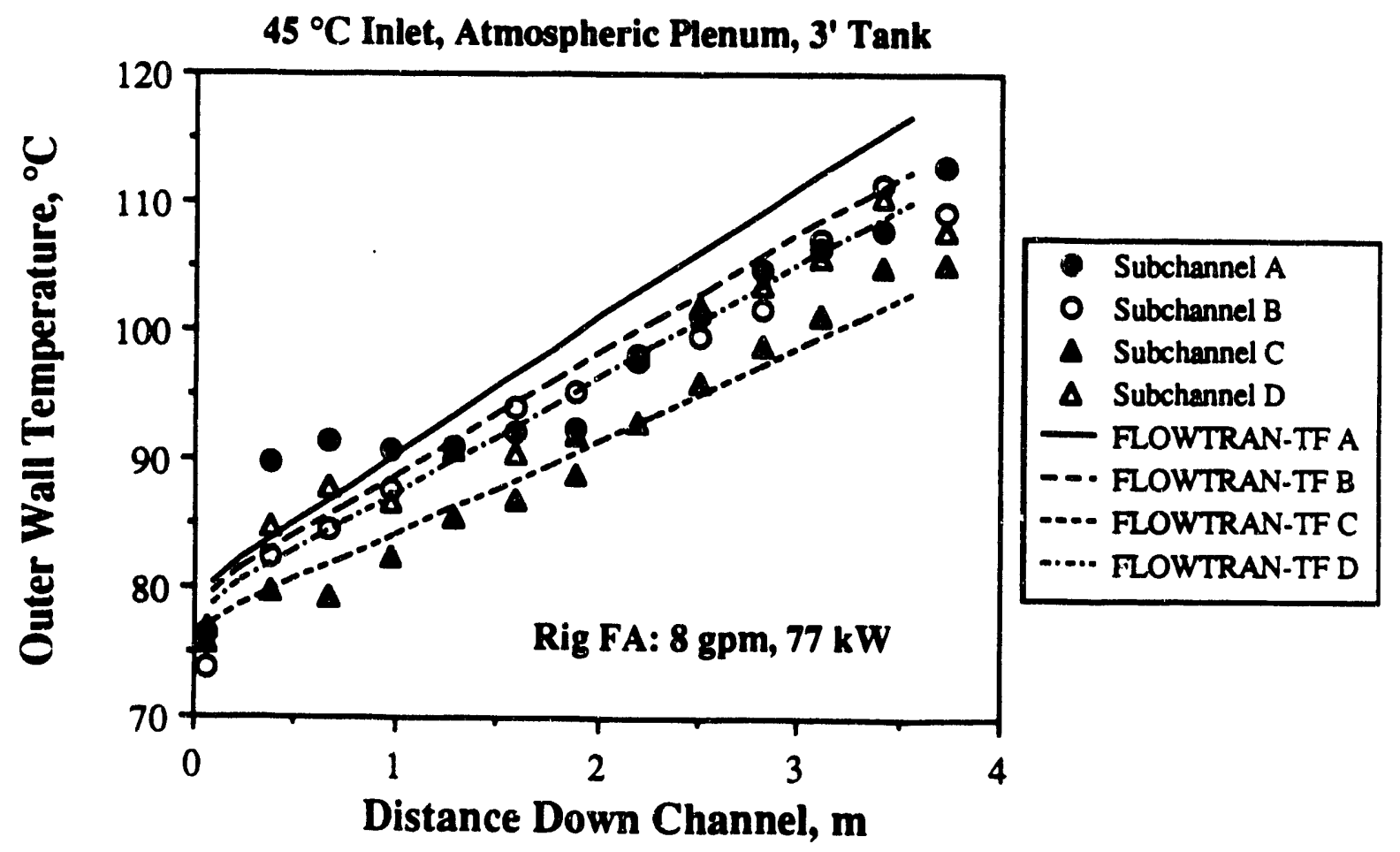

Figure 7.9 Wall temperatures in Rig FA compared to FLOWTRAN-TF predictions 


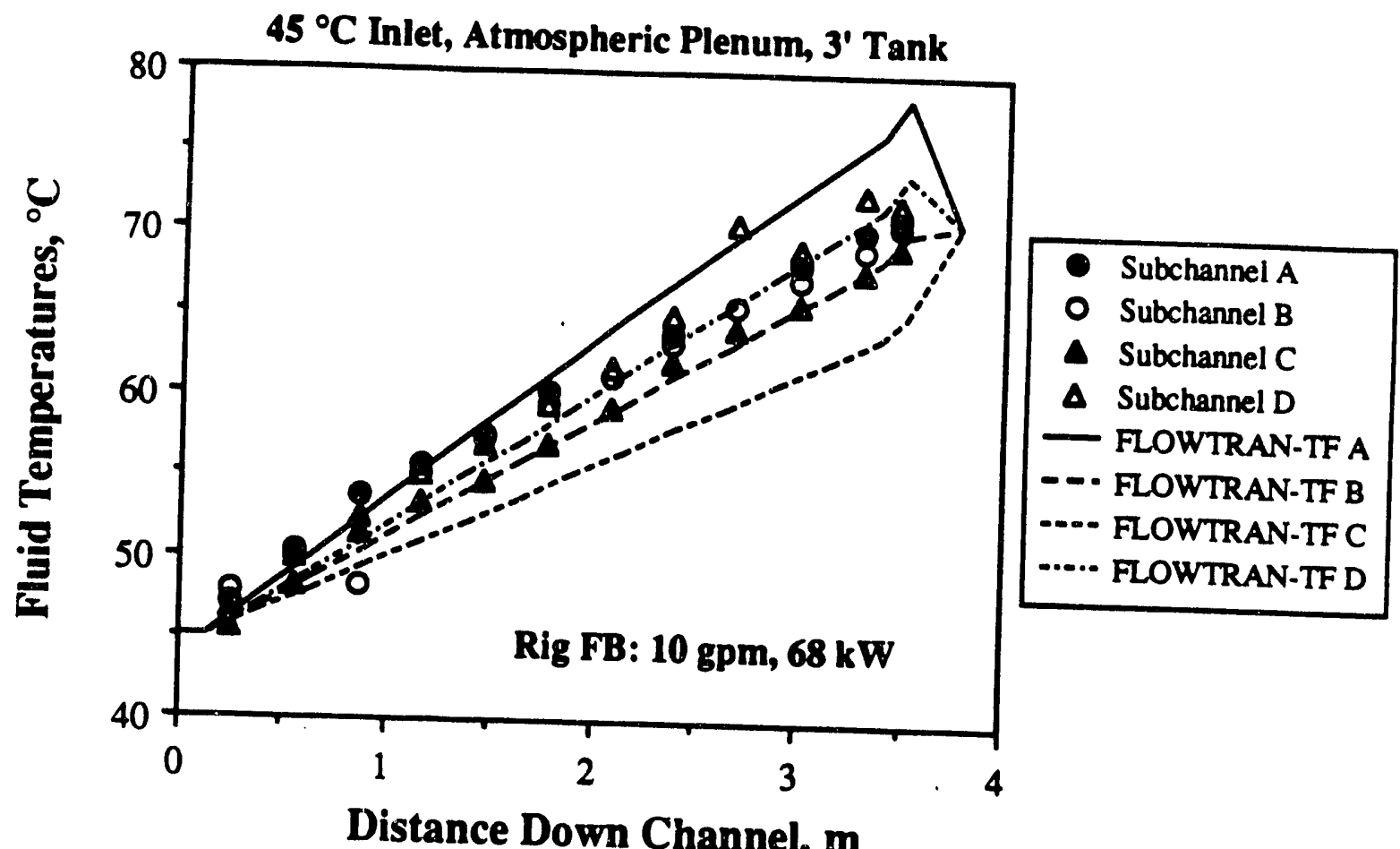

Figure 7.10 Fluid temperatures in Rig FB compared to FLOWTRAN-TF predictions

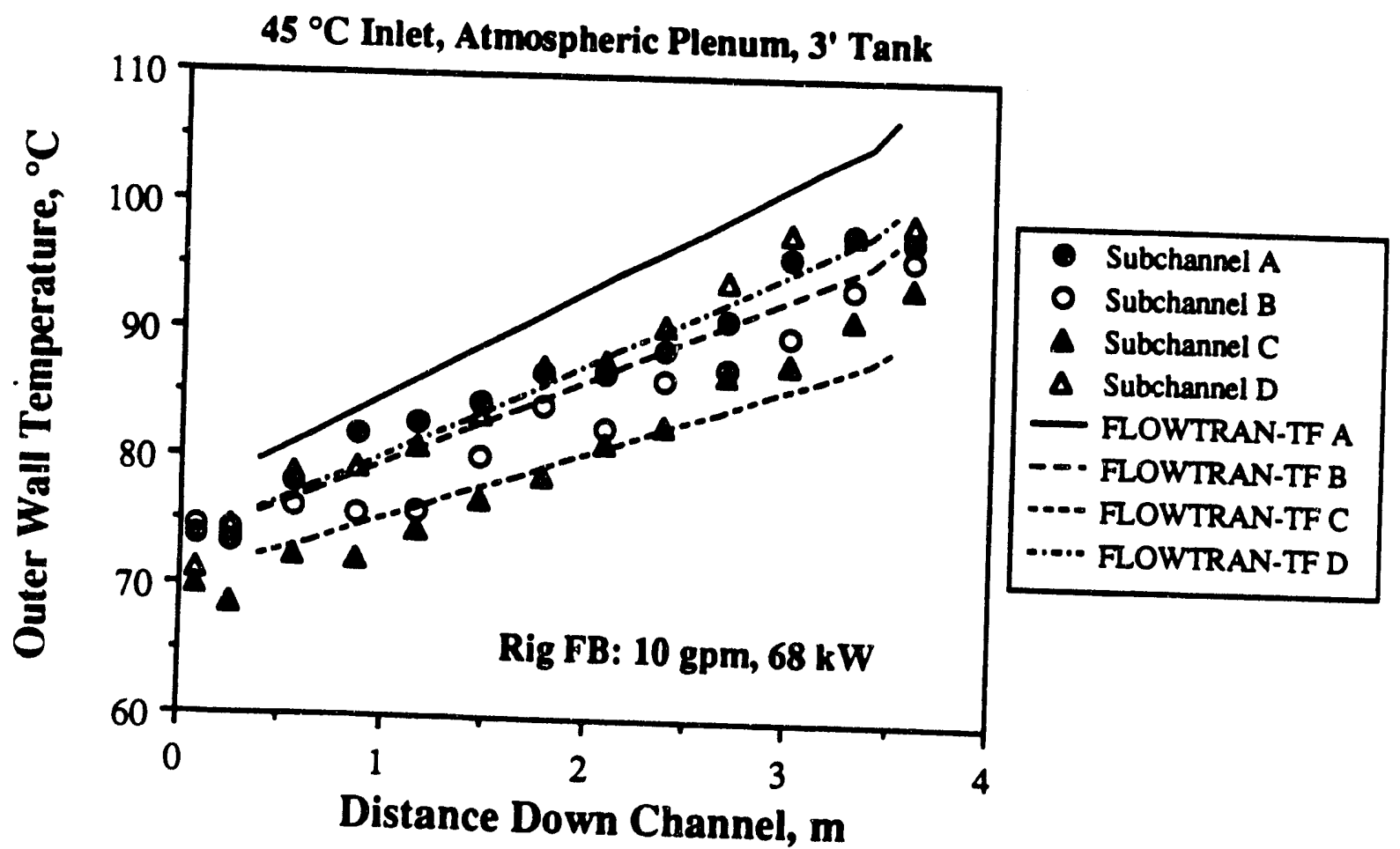

Figure 7.11 Wall temperatures in Rig FB compared to FLOWTRAN-TF predictions 


\section{Summary Assessment}

Table 8.1 summarizes the fluid constitutive relation benchmarking results presented in this report. In this section we concentrate on evaluating FLOWTRAN-TF as an ECS power limit tool. That is, we assess the fluid constitutive models in the context of their impact on the ECS power limit. The impact on power of a variable is controlled by two separate factors: the sensitivity coefficient, and the uncertainty of the independent variable. That is,

$$
\sigma_{p}=\sqrt{\sum\left(\frac{\partial p}{\partial x_{i}} \sigma_{i}\right)^{2}}
$$

where

$$
\begin{aligned}
\sigma_{\mathrm{p}} & \equiv \text { power uncertainty } \\
\sigma_{\mathrm{i}} & \equiv \text { independent variable uncertainty } \\
\partial \mathrm{P} / \partial \mathrm{x}_{\mathrm{i}} & \equiv \text { sensitivity coefficient }
\end{aligned}
$$

and the overall impact on the ECS power limit is given by the product $\left(\partial \mathrm{P} / \partial \mathrm{x}_{\mathrm{i}}\right) \sigma_{\mathrm{i}}$. Table 8.1 indicates this overall impact for each of the fluid constitutive relations as determined from the sensitivity analysis described by Smith et al. $(1990 \mathrm{~b})$. With the $T_{\text {wall }}=T_{\text {sat }}$ criterion, the ECS power limit is controlled mainly by channel and subchannel flow fractions and by the nonboiling heat transfer coefficient since these factors set the wall surface temperatures. Constitutive relations affecting the liquid flow distribution and/or heat transfer coefficient potentially have a significant impact on the power limit.

The wall friction drag model (Flach et al., 1990, 87) impacts the power limit mainly indirectly through the dispersed regime heat transfer coefficient. The dispersed regime correlation is a function of phasic liquid velocity which is defined by the void fraction for a given liquid flowrate. The wall friction model largely controls predicted void fraction. The power limit is not sensitive to the wall drag model, however, due to the excellent benchmarking comparisons which yield a relatively low model uncertainty. For ECS limits usage, the FLOWTRAN-TF wall friction model is considered satisfactory.

The wall form model (Flach et al., 1990, 87) for the Bottom Fitting Insert (BFI) of the Mark-22 was benchmarked against BFI pressure difference data from the AFD apparatus. The benchmark results are excellent, and nearly direct since the BFI pressure difference is controlled mainly by form losses. The BFI form loss model affects the power limit as follows. With a fixed overall assembly pressure difference, the BFI pressure difference clearly affects the pressure gradient in the heated section of a Mark-22. Void fraction varies with pressure gradient and void variations affect the dispersed regime heat transfer coefficient as previously discussed. The ECS power limit sensitivity results indicate a high overall impact. The high impact can probably be explained by the large uncertainty $( \pm 50 \%)$ assigned to the BFI form loss coefficient. In light of the excellent data comparisons shown in this document, a lower uncertainty is warranted. The wall form loss model in FLOWTRAN-TF is considered acceptable for ECS power limit computations. 
The interfacial drag model (Flach et al., 1990, \$10) benchmarking results are somewnat perplexing to-date. The single-channel VOID Rig comparisons are good but the Mark-22 air flowrate predictions are poor. Fortunately, the ECS power limit is not sensitive to this component of FLOWTRAN-TF. Nevertheless, additional model development is planned for the interfacial drag constitutive relation, especially since OTE power simulations, which define the physical safety margin, require accurate interfacial drag modeling. The CCFL aspect of the interfacial drag model is particularly important to accurate OTE modeling. For this reason, flooding (CCFL) data in ribbed annular channels would be desirable to verify the literature based CCFL correlation incorporated into the FLOWTRAN-TF drag model is appropriate.

The Mar:-22 channel inlet void distribution model (Flach et al., 1990, 811 ) has a high impact on power since this model largely sets the individual channel liquid flowrates. The model was developed from only a subset of the data available now. Since this model is important to the ECS power limit, additional development is planned to incorporate all available data into the correlations.

The overall azimuthal momentum balance includes rib void fraction donoring (Flach et al., 1990, \$12), form loss (Flach et al., 1990, \$7), interfacial drag (Flach et al., 1990, \$10), and geometry elements. None of the these have been directly benchmarked. The heated, single-channel results are affected by the azimuthal momentum model. These. integral benchmarks are reasonably good and provide assurance that the model is adequate. Nevertheless, lacking direct benchmarking data, large model uncertainties have been chosen and their impact on power is high. The ECS power limit is inherently sensitive to the azimuthal momentum model since subchannel flow maldistributions result from azimuthal crossflows. Additional model development, largely depending on new experimental data, would reduce the model uncertainty contribution to the ECS power level uncertainty.

Like the azimuthal momentum balance, the entire interfacial heat and mass transfer package (Flach et al., 1990, \$8 \& 9) is largely untested. Fortunately, this constitutive relation has virtually no impact on the power limit. However, the predicted OTE power level is affected. The heated, single channel OTE comparisons do provide a integral test of FLOWTRAN-TF involving significant interfacial heat and mass transfer. The precise performance of the interfacial heat and mass transfer model is indeterminate however.

The nonboiling heat transfer correlations (Flach et al., 1990, 86) are very important to the ECS power limit since they define wall surface temperatures which are critical to the $T_{\text {wall }}=$ $T_{\text {sat }}$ criterion. Fortunately, the correlations were derived from prototypic air-water downflow data from a ribbed annular passage. The data exhibits a large scatter which is thought to be mainly experimental error rather than model deficiency. Nevertheless, work is currently in progress to acquire accurate prototypic heat transfer data for evaluating/developing nonboiling heat transfer correlations.

The boiling heat flux and wall vaporization rate models (Flach et al., 1990, 86 \& 9) are not invoked in ECS power limits calculations so they have no impact. Obviously, these models do impact the predicted OTE power level. Therefore, benchmarking comparisons for these components of FLOWTRAN-TF are important only in assessing the computed safety margin between the conservative estimate power limit and the predicted OTE power. The in-progress work mentioned above will also include accurate boiling heat transfer data up to CHF and allow direct evaluation/development of pre-CHF boiling correlations. 
Azimuthal crossflow, heat transfer, and interfacial drag modeling (to some extent) have been identified as the areas in which FLOWTRAN-TF could be improved to raise the conservative-estimate ECS power limit. Because there exists a significant margin between the Recommended K-Reactor Restart ECS Power Limit and the Flow Instability (FI) phase power limit, FLOWTRAN-TF upgrades are not viewed as critical to reactor restart. In this sense, FLOWTRAN-TF coupled with the overall ECS limit methodology is considered adequate for setting safe reactor power levels.

Table 8.1 Summary of FLOWTRAN-TF fluid constitutive relation benchmarking and impact of constitutive relations on ECS power limit

\begin{tabular}{|c|c|c|c|}
\hline $\begin{array}{l}\text { CONSTITUTIVE } \\
\text { RELATION }\end{array}$ & $\begin{array}{c}\text { DIREC' } \\
\text { BENCHMARK }\end{array}$ & $\begin{array}{l}\text { INDTRECT } \\
\text { BENCHMARK } \\
\text { (INTEGRAL) }\end{array}$ & $\begin{array}{l}\text { MMPACT ON } \\
\text { ECS POWER } \\
\text { LIMIT }\end{array}$ \\
\hline $\begin{array}{l}\text { Friction Wall } \\
\text { Drag }\end{array}$ & $\begin{array}{c}\text { Void fraction - } \\
\$ 2 \\
\text { Excellent results }\end{array}$ & 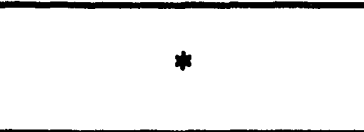 & $\begin{array}{l}\text { Low } \\
\text { (Affects heat transfer } \\
\text { coefficient) }\end{array}$ \\
\hline Form Wall Drag & None & $\begin{array}{c}\text { BFI pressure } \\
\text { difference }-86.2 \\
\text { Excellent results }\end{array}$ & $\begin{array}{c}\text { High } \\
\text { (Affects pressure } \\
\text { gradient in heated } \\
\text { core) }\end{array}$ \\
\hline Interfacial Drag & $\begin{array}{l}\text { Air flowrate }-\overline{83} \\
\text { Good results }\end{array}$ & $\begin{array}{c}\text { Mark-22 } \\
\text { assembly air } \\
\text { fowrate - 86.1 } \\
\text { Poor results }\end{array}$ & Low \\
\hline $\begin{array}{c}\text { Mark-22 Channel } \\
\text { Inlet Void } \\
\text { Distribution }\end{array}$ & $\begin{array}{c}\text { Channel liquid } \\
\text { now fraction - } \\
\$ 4 \\
\text { Good results }\end{array}$ & 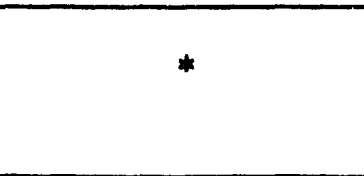 & $\begin{array}{c}\text { High } \\
\text { (Affects channel } \\
\text { liquid flow fraction) }\end{array}$ \\
\hline $\begin{array}{c}\text { Azimuthal } \\
\text { Momentum } \\
\text { Balance }\end{array}$ & None & $\begin{array}{l}\text { Heated single- } \\
\text { channel - } \$ 7 \\
\text { Twall - good results } \\
\text { OTE - fair results }\end{array}$ & $\begin{array}{c}\text { High } \\
\text { (Affects subchannel } \\
\text { liquid flow fraction) }\end{array}$ \\
\hline $\begin{array}{c}\text { Flow Regime } \\
\text { Map/ } \\
\text { Interfacial Area/ } \\
\text { Interfacial Heat } \\
\text { \& Mass Transfer }\end{array}$ & None & $\begin{array}{l}\text { Heated single- } \\
\text { channel - } 87 \\
\text { Twall - good results } \\
\text { OTE - fair results }\end{array}$ & $\begin{array}{l}\text { Almost none } \\
\text { (No wall boiling; } \\
\text { small evaporation in } \\
\text { bulk flow) }\end{array}$ \\
\hline $\begin{array}{c}\text { Nonboiling Heat } \\
\text { Transfer }\end{array}$ & $\begin{array}{l}\text { Heat transfer } \\
\text { coefficient - \$5 } \\
\text { Good results } \\
\text { (Large data } \\
\text { uncertainty however) }\end{array}$ & * & $\begin{array}{c}\text { High } \\
\text { (Affects wall surface } \\
\text { temperature) }\end{array}$ \\
\hline $\begin{array}{l}\text { Boiling Heat } \\
\text { Transfer }\end{array}$ & None & $\begin{array}{l}\text { Heated single- } \\
\text { channel - \$7 } \\
\text { Twall - good results } \\
\text { OTE - fair results }\end{array}$ & $\begin{array}{c}\text { None } \\
\text { (No boiling with } \\
\mathrm{T}_{\text {wall }}=\mathrm{T}_{\text {sat }} \text { criterion) }\end{array}$ \\
\hline
\end{tabular}

* Direct benchmark already available 


\section{References}

Childerson, M. T., Manolescu, M. I., and Parkinson, J. R., 1990, "Annular Flow Distribution Test - Interim Report", Babcock and Wilcox Alliance Research Center Report RDD:90:4558-05-01:01 and WSRC-TR-90-149.

ETH/NES, 1990, private communication.

Flach, G. P., Aleman, S. E., Hamm, L. L., Lee, S. Y., Smith, F. G., III, and Van Brunt, V., 1990, "FLOWTRAN-TF Code Description (U)", WSRC-TR-90-413.

Guerrero, H. N., 1990, private communication.

Johnston, B. S., 1990a, WSRC-TR-90-45.

Johnston, B. S., 1990b, "Preliminary Release of Data for Experiment FB 03/07 1830", March 7, 1990 private communication.

NES-CDG-900015, 1990.

Smith, F: G., III, Hamm, L. L., and Koffman, L. D., 1990, "DEGB LOCA ECS Limits Methodology (U)", WSRC-TR-90-411.

Smith, F. G., III, Aleman, S. E., Flach, G. P., Hamm, L. L., Koffman, L. D., and Lee, S. Y., 1990, "DEGB LOCA ECS Power Limit Recommendation for K-14.1 Subcycle (U)", WSRC-TR-90-412.

Steimke, J. L., 1990a, WSRC-TF-90-44.

Steimke, J. L., 1990b, "Rig FA Data to Support Tsat Criterion, 8 gpm", NES-ECS900308.

Whatley, V., 1990, "Measurements of Void Fractions and Pressure Profiles for Downward Flowing Air-Water Mixtures in Single Test Annulus (U)", WSRC-TR-90-328. 

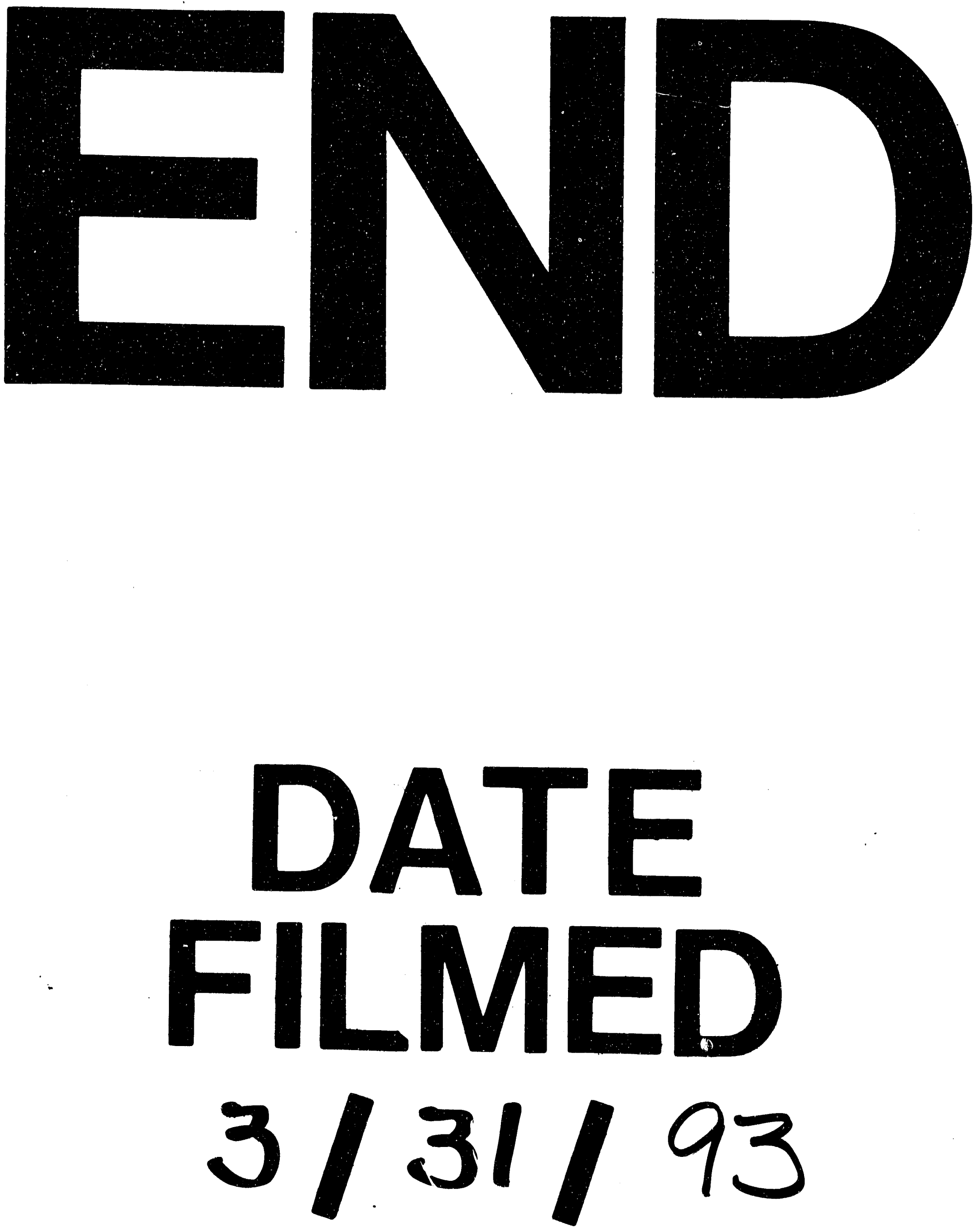
